\title{
Housing Demand During the Boom: The Role of Expectations and Credit Constraints
}

\author{
Tim Landvoigt* \\ Stanford University
}

July 2010

\begin{abstract}
Optimism about future house price appreciation and loose credit constraints are commonly considered as having been the main drivers of the recent housing boom. This paper examines the role these two forces played in shaping household behavior during the boom by inferring short-run expectations of future house price growth and minimum down payment requirements from observed household choices. The expectations and credit constraints are implied by a lifecycle portfolio choice model that encompasses home ownership, housing demand, and financing choices. I structurally estimate the parameters of this model using data from the Survey of Consumer Finances from 1995 to 2007. The main result is that both aggregate expectations of future price growth and down payment requirements were declining throughout the boom. The falling expectations moderate the otherwise counterfactually strong rise in house values predicted by the model. Laxer credit constraints partly offset the effect of the drop in expecations and lead to the slight increases in loan-to-value ratios and the home ownership rate that we observe in the data for this time period. The lower expectations at the end of the boom could be interpreted as evidence for aggregate beliefs in mean-reverting house prices.
\end{abstract}

*timl@stanford.edu I am grateful to my adviser Martin Schneider for his guidance, and to Monika Piazzesi for many helpful discussions. I have also benefited from comments by Manual Amador, Doug Bernheim, Tim Bresnahan, Max Floetotto, Bob Hall, Nir Jaimovich, Seema Jayachandran, Ken Judd, Pete Klenow, Johannes Stroebel, Michèle Tertilt, and participants of the Stanford Macro Lunch seminar and 3rd-year seminar. 


\section{Introduction}

The key features of the recent housing boom were a sharp increase in prices with stable rents in the market for residential real estate, and low interest rates and loose lending standards in the mortgage market. They characterize the economic environment that households were facing when

they were deciding whether to rent or own their residence, whether to upgrade or downgrade the house they own, or whether to re-finance their mortgage. A generally unobserved but important determinant of such decisions is the expected rate of house price growth that households assume in their decision-making process.

It is a wide-spread notion that the housing boom and the associated increase in household debt were partly fueled by overly optimistic expectations about future returns to housing. This notion is consistent with most existing survey evidence about house price expectations. Case and Shiller (2003) present survey evidence that past booms in the housing market were generally linked to optimistic expectations about future price growth. For the case of the recent housing boom, Piazzesi and Schneider (2009) report based on the Michigan Survey of Consumers that the share of households explicitly believing in rising house prices increased throughout the boom from 10 percent to a peak value of about 20 percent in 2005, after which it started to slowly decline again.

Directly surveying households about their expectations of future prices is a possible way of obtaining a measure of this otherwise unobserved quantity. However, the existing survey evidence for the recent housing boom is limited in scope and not quantitative. A different approach that I take in this paper is to estimate model-implied expectations from observed household choices, under some assumptions on the belief structure. In other words, given a model of optimal housing demand, for which expectations about future house prices are an input parameter, it is possible to back out implied expectations from observed demand.

Most academic studies of the boom focus on household debt and particular segments of the mortgage market that are considered the driving force of the boom. Several household-level studies such as Mayer, Pence, and Sherlund (2009) and Mian and Sufi (2009) provide evidence that both new home buyers and existing homeowners took advantage of the favorable conditions in the mortgage market. This paper takes a broader view of the boom, in the sense that it does not only 
focus on the segments of the housing and mortgage markets that were the most active in terms of transactions and increases in leverage. Further, it connects the financing side of observed household choices during the boom with the extensive and intensive margins of housing demand, i.e. the decision whether to rent or own and the amount of housing services consumed. To accomplish this, I solve a life-cyle portfolio choice model with housing, and use the optimal policies to estimate expectations and credit constraints with data from the Survey of Consumer Finances (SCF) for the period 1995 to $2007^{1}$.

We can think of the optimal policies resulting from the dynamic program as a mapping from different dimensions of household heterogeneity - age, income, wealth, homeownership status, and the house owned initially - into choices for the next period - homeownership status, house value, consumption of services and numeraire, and the amount saved or borrowed. By assigning these optimal policies to all observations in the SCF for a given year, and then simulating the transition of the updated state variables forward, one gets a simulated sample for the next year. Thus using a pseudo-panel approach in the spirit of Browning, Deaton, and Irish (1985), one can estimate the model parameters by Simulated Method of Moments (SMM) from repeated cross-sections.

The methodological contribution of this paper is the way household beliefs are structured short-term beliefs dictate expectations for the next period, and long-term beliefs based on longrun averages apply to all subsequent life-cycle periods. At the same time, short-term observable variables that households take as given, such as house price-to-rent ratios, interest rates, and mortgage spreads, are set to their actual value for each period. This way I can use the model to trace short-term time-variation in these exogenous variables, and estimate the matching short-term expectations, while keeping long-term household beliefs about all variables set to long-run averages.

The main finding is that average household expectations were relatively high with a value of $3 \%$ appreciation annually in 1995, and declined throughout the boom. The estimated expectations during the boom for the period 2004 to 2007 are slightly negative and close to zero. This estimate results in combination with a simultaneous estimated decrease of the average down payment constraint from a value of close to $30 \%$ to $14 \%$ (as share of the house value at the time of the purchase)

\footnotetext{
${ }^{1}$ The SCF is only conducted every three years, thus the total sample consists of the cross-sections in 1995, 1998, 2001, 2004, and 2007.
} 
from 1995 to 2004 . Low interest rates and strong realized house price gains push up the modelpredicted house values during boom to the extent that they would be too large compared to the data if expecations of future price growth had remained high. Hence the lower expectations during the boom are needed to rationalize the only moderate increase of house value-to-income ratios in the data. Everything else equal, the low price growth expectations would depress model-implied loan-to-value ratios and home ownership rates. The role of the the relaxed down payment constraint is thus to offset the effect of the falling expectations and induce slight increases in leverage and home ownership to match the data. The separate identification of the two forces (expectations and down payment constraints) affecting household choices comes from their differential impact on the intensive and extensive margins of housing demand. In particular, changes of the down payment constraint only have a quantitatively small effect on the intensive margin.

A low elasticity of substitution (i.e. complementarity) between housing services and other goods plays an important role in the above identification argument. Complementarity between the two goods causes the optimal housing expenditure to rise with the relative price of housing during the boom, which leads to the strong model-implied rise in house values and ultimately the estimated downward trend in expectations. I jointly estimate the elasticity parameter with the expecations and credit constraints, and the estimate of high complementarity between the two goods results from the need to explain the relative stability of homeownership rates over time. If housing services and numeraire consumption are complements, life-cycle considerations influenced by the magnitude of the credit constraints dominate households' optimal own vs. rent decision. If both goods were closer to substitutes, however, temporary user-cost considerations become more important in the ownership decision, and the model would predict too high home ownership rates in 1998 and too low rates in 2007 as house prices -but not rents- rise during the boom.

The model presented in this paper is similar to the models developed by Campbell and Cocco (2003), Cocco (2004), and Yao and Zhang (2005a). These papers focus on introducing housing as an additional asset in a portfolio choice setting with life-cycle labor income. They solve for optimal life-cycle positions of housing and other assets such as bonds and stocks; their emphasis is on analyzing the optimal policies for a given calibration that uses parameter values from the 
literature. Other more recent partial equilibrium studies using a similar model and extensions thereof are Yao and Zhang (2005b), Li and Yao (2007), Li, Liu, and Yao (2009), and Bajari, Chan, Krueger, and Miller (2010). Yao and Zhang (2005b) extend the model of Yao and Zhang (2005a) by introducing additional realistic frictions in the mortgage market such as long-term fixed-rate contracts and a cost for refinancing. Their focus is again on the properties of the optimal life-cycle portfolio choice. Li and Yao (2007) analyze the welfare effects of house price changes for different age groups, and homeowners and renters. The works of Li, Liu, and Yao (2009) and Bajari, Chan, Krueger, and Miller (2010) are most related to this paper in terms of methods, since the authors perform a structural estimation of a life-cycle model with housing similar to the one in this paper, using data from the PSID. However, their focus is mainly on using the fitted model to conduct experiments and predict future household behavior. While Li, Liu, and Yao (2009) focus on policy experiments about changes in lending conditions, Bajari, Chan, Krueger, and Miller (2010) are predicting the length and depth of the slump in the housing market. In contrast to the analysis of this paper, all of the papers listed above assume that household beliefs about future house prices are described by the same stochastic process over the life-cycle, irrespective of current economic conditions. This process is usually parametrized based on long-run historical averages.

The econometric methodology in this paper draws on the general results on SMM estimators from Pakes and Pollard (1989), and the application by Hall and Rust (2002) to the case of a dynamic model with non-convex adjustment cost.

This paper proceeds as follows. Section 2 describes the model, discusses the assumptions, and outlines the computational solution method. Section 3 discusses the empirical strategy and its implementation, and states values of the calibrated parameters and data source. Section 3 also reports on the samples and exact variables used from the SCF. Section 4 presents the data moments entering the objective function and the estimation results. It further discusses the identification, and interprets the findings. Section 5 concludes. 


\section{Model}

\subsection{Household Problem}

A household lives for years $t=25, \ldots, 100$, with a probability of survival from year $t-1$ to $t$ of $\lambda_{t}$, and $\lambda_{T+1}=0$. Every year until retirement at age $t_{R}=65$, the household receives labor income $Y_{t}$ that follows an exogenous stochastic process. After retirement, the household receives a constant fraction of its last labor income $Y_{t_{R}}$ until death. The household chooses consumption of housing services $S_{t}$ and a numeraire good $C_{t}$ every year to maximize expected lifetime utility given by

$$
\mathrm{E}_{t}\left\{\sum_{t=0}^{T} \beta^{t}\left[\Lambda_{t} \lambda_{t+1} u\left(C_{t}, S_{t}\right)+\Lambda_{t}\left(1-\lambda_{t+1}\right) B_{t}\right]\right\},
$$

where $B_{t}$ is the bequest the household leaves to its children in case it does not survive until year $t+1$, and

$$
\Lambda_{t}=\prod_{s=0}^{t} \lambda_{s}
$$

is the unconditional probability that the household is alive in year $t<T$. The temporary utility function $u(C, S)$ is assumed to satisfy the usual properties of being stringly increasing and concave in both arguments.

Housing has the dual role of an asset that the household can save in, and a durable consumption good that generates housing services. A house of size $H_{t}$ produces housing services with the linear technology $S_{t}=H_{t}$. In order to consume the service amount $S_{t}$, the household can either own or rent a house of size $H_{t}$. In both cases, the house produces the same amount of services. A unit of the housing asset sells for $P_{t}$ units of numeraire in year $t$, and can be rented for $P_{t}^{r}$ in the rental market.

The household assumes that labor income and house price follow a Markov process with transtion rule

$$
\left[Y_{t}, P_{t}\right]=F\left(\left[Y_{t-1}, P_{t-1}\right], \epsilon_{t}\right)
$$

where $\epsilon_{t}$ is a two-dimensional random vector distributed independently over time. I will specify the exact form of the transition rule below. 
The rental price is pegged to the asset price through a deterministic, but potentially timevarying ratio

$$
\alpha_{t}=\frac{P_{t}^{r}}{P_{t}}
$$

In addition to the housing asset, the household can save and borrow the amount $L_{t}$ in a risk-free bond. By saving one unit of numeraire in the bond at $t-1$, the bond pays out $R_{t}>1$ units at $t$. Borrowing one unit at $t-1$ requires a payment of $R_{t}+\zeta_{t}$ at $t$, with $\zeta_{t}>0$. In order to borrow, the household has to own a house and use part of its value as collateral. In particular, when the household buys a house, it can at most borrow an amount $\left(1-\delta_{t}\right)$ of the house value to finance the purchase, where $\delta_{t}$ is the fraction required as a downpayment

$$
L_{t} \geq-\left(1-\delta_{t}\right) P_{t} H_{t}
$$

The budget constraint and the evolution of household wealth over time are best understood by distinguishing two cases. First, if the household did not own a house at age $t-1$, its liquid resources in period $t$ consist of savings and interest from the previous period and current labor income. The household can use this wealth to consume the numeraire good, buy or rent units of the housing asset, and save in the risk-free asset. If the household decides to buy a house (i.e. purchase a postive amount of the housing asset), it can also borrow in the risk-free asset subject to constraint 3. Since the borrowing rate is greater than the rate for savings, the household will never optimally save and borrow at the same time. Thus it suffices to keep track of the net position $L_{t}$ in the risk-free asset. Denoting the decision whether to own or rent in period $t$ by $\tau_{t} \in\{0,1\}$, with 0 indicating renting and 1 buying, this yields the following budget constraint for a household who was renting in period $t-1$

$$
R_{t} L_{t-1}+Y_{t}=C_{t}+L_{t}+P_{t} H_{t}\left[\left(1-\tau_{t}\right) \alpha_{t}+\tau_{t}(1+\psi)\right]
$$

subject to the downpayment constraint 3 , and using the fact that the rental price can be expressed in terms of the house price and the rent-to-price ratio $\alpha_{t}$ based on equation 2 . The coefficient $(1+\psi)$ multiplying the expenditure on the new house in the last term accounts for a proportional maintenance cost $\psi P_{t} H_{t}$ that a homeowner must pay each period in order to offset depreciation. 
The second case is that of a household who enters period $t$ owning a house. The household may sell its current house in order to buy a new one of different size or rent instead. In this case, the sale requires payment of a transaction cost proportional to the house value, $\nu P_{t} H_{t-1}$. In general, the homeowner can decide to stay in the current house, and therefore not incur the transaction cost. Hence the homeowner's liquid resources consist of savings and labor income as for the renter, plus the value of the house net of the mortgage principal and interest. Denoting the decision whether to sell or keep the house by $\sigma_{t} \in\{0,1\}$, with 0 indicating keeping the house and 1 selling, the constraint for the homeowner is

$$
\begin{aligned}
\left(R_{t}+1\left[L_{t-1}<0\right] \zeta_{t}\right) L_{t-1}+Y_{t}+P_{t} H_{t-1}= & C_{t}+L_{t}+\left(1-\sigma_{t}\right) P_{t} H_{t-1} \\
& \sigma_{t}\left\{P_{t} H_{t}\left[\left(1-\tau_{t}\right) \alpha_{t}+\tau_{t}(1+\psi)\right]+\nu P_{t} H_{t-1}\right\}
\end{aligned}
$$

again subject to downpayment constraint 3 , and with $\tau_{t}$ indicating the homeownership decision as in equation 4 .

Each household has to move with a certain probability every period, independent of all other shocks and previous periods. This shock is only relevant for homeowners since it forces them to sell their house and incur the transaction cost. Renters sign period-by-period rental contracts, and thus their problem is unaffected. Let the outcome of this shock be denoted by $M_{t} \in\{0,1\}$, with 0 indicating that the household may keep the house and 1 that it must move.

The complete life-cycle optimization problem can be stated recursively using dynamic programming. Denote the vector of state variables at time $t$ by $X_{t}=\left[M_{t}, P_{t}, \tau_{t-1}, H_{t-1}, Y_{t}, L_{t-1}\right]$, and the vector of choice variables $Z_{t}=\left[\tau_{t}, \sigma_{t}, H_{t}, C_{t}, L_{t}\right]$. Then the value function at age $t=0, \ldots, T-1$ is defined as

$$
V_{t}\left(X_{t}\right)=\lambda_{t+1}\left\{\max _{Z_{t}} u\left(C_{t}, S_{t}\right)+\beta \mathrm{E}_{t}\left[V_{t+1}\left(X_{t+1}\right)\right]\right\}+\left(1-\lambda_{t+1}\right) B\left(X_{t}\right)
$$

subject to constraints 3, 4, and 5 and the transition equation for income and prices 1, and by

$$
V_{T}\left(X_{T}\right)=B\left(X_{T}\right)
$$

for the final period.

To close the model, I still need to specify functional forms for the intra-period utility function 
$u(C, S)$ and the bequest function $B(X)$. For the utility, I use the conventional CES form

$$
u(C, S)=\frac{\left[(1-\rho) C^{1-1 / \eta}+\rho S^{1-1 / \eta}\right]^{\frac{1-\gamma}{1-1 / \eta}}}{1-\gamma},
$$

where $\eta$ is the elasticity of substitution between housing services and numeraire consumption, $\rho$ a paramter determining the relative weight on housing services, and $\gamma$ is the parameter governing risk-aversion. For the bequest function, I follow Yao and Zhang (2005a) in assuming that in the event of its death the household wants to provide a $J$-year annuity to its children. By providing this annuity, the households aims to support consumption and rental expenditure of its children according to the Cobb-Douglas weights $1-\omega$ and $\omega$, respectively. This yields a consistent way of modeling the bequest motive in the sense that bequest utility is strictly increasing in liquid resources given by state $X_{t}$. It further allows for controlling the strength of this motive through parameter $J$. The reader is referred to appendix A for a detailed description.

\subsection{Computational Solution}

The state and the choice variables of the dynamic program given by equations 6 and 10 can be re-defined to allow for a more efficient computational solution. These transformations are also the basis for the mapping of model quantities to observables described in the next section, so I will state the important aspects here and refer the reader to appendix A for details on the transformed model and the computational approach.

First, define household liquid funds after a hypothetical sale of the current house for homeowners as

$$
W_{t}=R_{t} L_{t-1}+\tau_{t-1}(1-\nu) P_{t} H_{t-1}+Y_{t}
$$

Now normalize all model quantities by current income $Y_{t}$, which is equivalent to normalization by permanent income due to the i.i.d. nature of the innovations to income growth. Specifically, define $w_{t}=W_{t} / Y_{t}$ and $\bar{h}_{t-1}=P_{t} H_{t-1} / Y_{t}$ for the state variables and $c_{t}=C_{t} / Y_{t}, l_{t}=L_{t} / Y_{t}$ and $h_{t}=P_{t} H_{t} / Y_{t}$ with respect to choices. All housing related quantities are expressed in terms of expenditure since this is what we observe in the data. I reduce the choices of both owner and renter to the value of the occupied house $h_{t}$, which is possible due to the linearity housing services production from the housing asset. Thus letting the vector of transformed state variables be given 
by $x_{t}=\left[M_{t}, P_{t}, \tau_{t-1}, w_{t}, \bar{h}_{t-1}, l_{t-1}\right]$ and the vector of choice variable by $z_{t}=\left[\tau_{t}, \sigma_{t}, h_{t}, c_{t}, l_{t}\right]$, one can define the normalized value function $v_{t}\left(x_{t}\right)=V_{t}\left(X_{t}\right) / Y_{t}^{1-\gamma}$ to get

$$
\begin{aligned}
v_{t}\left(x_{t}\right)= & \lambda_{t+1}\left\{\max _{z_{t}} \frac{\left[(1-\rho) c_{t}^{1-1 / \eta}+\rho\left(h_{t} / P_{t}\right)^{1-1 / \eta}\right]^{\frac{1-\gamma}{1-1 / \eta}}}{1-\gamma}+\beta \mathrm{E}_{t}\left[v_{t+1}\left(x_{t+1}\right) \frac{Y_{t+1}}{Y_{t}}\right]\right\} \\
& +\left(1-\lambda_{t+1}\right) b\left(t_{j}\right)
\end{aligned}
$$

subject to conformably rewritten budget and downpayment constraints given in appendix A.

In practice, the computation is best performed in terms of two different value functions (both normalized by income) and the resulting optimal policies: one for households who were renting in the previous period or those who were forced to sell and move due to the exogenous shock, and one for homeowners that have the additional option of staying in their current house. Appendix A contains details on these transformed value functions and the corresponding budget constraints and transition equations for the states. Due to the nature of the estimation procedure, the model's solution will have to be re-computed for each iteration of the estimation loop. This calls for a fast implementation of the dynamic programming solution. Therefore, the time-critical parts of the computation are programmed in $\mathrm{C}$.

An important feature of the given formulation is the fact that the current price generally remains

a state-variable. Only for the special case of Cobb-Douglas utility $u(C, S)=\frac{\left(C^{1-\rho} H^{\rho}\right)^{1-\gamma}}{1-\gamma}$ that results from taking the limit $\eta \rightarrow 1$ in equation 8 is it also possible to normalize by the price $P_{t}$. In this case, the price level is not relevant for the optimal policy, and only the expected return matters (see e.g. Yao and Zhang (2005a)). For the empirically relevant case of complementarity between housing services consumption and numeraire consumption corresponding to $\eta<1$, however, the price level affects the optimal policy. Intuitively, at higher prices the household can only buy less housing services for a given expenditure level, and due to complementarity with numeraire consumption the optimal housing expenditure is higher.

\subsection{House Price and Labor Income Processes}

Since the empirical analysis will involve cross-sections of households of different age cohorts, for the remainder of the paper I will use the subscript $t$ to index the calendar year, and $i$ to index an individual household. The age of household $i$ in year $t$ will be denoted by $a_{i t}$. 
A crucial step in inferring household expectations from observed decisions is the modeling of household beliefs about future house prices. This involves specifying a parametric form for the transition rule $F\left(\left[Y_{i t-1}, P_{i t-1}\right], \epsilon_{i t}\right)$ in equation 1 for income and house prices. First, I assume that all households face the same aggregate house price that follows a random walk in logs, i.e.

$$
P_{t}=P_{t-1} \exp \left(m_{t-1}+\epsilon_{1, t}\right)
$$

where $\epsilon_{1, t}$ is an i.i.d. random variable with zero mean, an $m_{t-1}$ is the deterministic drift. The idiosyncratic labor income for household $i$ in year $t$ also follows a random walk in logs

$$
Y_{i t}=Y_{i t-1} \exp \left(f\left(a_{i t}\right)+g_{t}+\epsilon_{2, i t}\right),
$$

where $f\left(a_{i t}\right)$ is a deterministic life-cycle trend, $g_{t}$ is the deterministic aggregate income growth in year $t$, and $\epsilon_{2, i t}$ is a random variable that is i.i.d. over time. I assume that $\epsilon_{2, i t}$ has an aggregate and an idiosyncratic component. The aggregate component of $\epsilon_{2, i t}$ is positively correlated with the innovation to aggregate house price growth $\epsilon_{1, t}$, i.e. one can write

$$
\epsilon_{2, i t} \equiv u_{t}+\kappa_{i t}
$$

where $\operatorname{Corr}\left(u_{t}, \epsilon_{1, t}\right)>0$, and $\kappa_{i t}$ is i.i.d. across households implying $\operatorname{Corr}\left(\kappa_{i t}, \epsilon_{1, t}\right)=0$.

This specification deserves some discussion. First, from the perspective of the optimizing household the distinction between aggregate and idiosyncratic labor income risk is only important (in the context of this analysis) to the extent that it induces a positive correlation between income and house price growth. In other words, household $i$ only cares about the joint distribution of $\left(\epsilon_{1, t}, \epsilon_{2, i t}\right)$. The positive correlation between the two innovations captures the fact that regional house prices are often affected by labor income shocks in the same region.

Secondly, equation 11 implies that at any given date $t$ all households agree on a deterministic sequence specifying expected house price growth for all future periods $\left\{m_{t+s}\right\}_{s=0}^{\infty}$. Put differently, expected house price growth from year $t+s$ to year $t+s+1, s \geq 0$, is for all households given by

$$
\mathrm{E}_{t+s}\left[\log \left(P_{t+s+1}\right)-\log \left(P_{t+s}\right)\right]=m_{t+s}
$$

which is known with certainty at date $t$. 


\subsection{Discussion}

Several assumptions deserve a brief discussion. First, I assume throughout that the household can either buy a house and consume its services in full, or hold no housing asset and buy the desired amount of services in the rental market. The model does therefore not address the supply decision of rental units, which would correspond to some households holding more of the housing asset than they consume housing services and selling the excess services in the rental market. However, the formulation chosen here captures the relevant housing choices for the large majority of U.S. households - in the 2007 SCF only about $14 \%$ of households own real estate other than their primary residence. Further, given the partial equilibrium approach and the focus on household beliefs, an analysis of the interaction between rental and housing markets during the boom is not in the scope of this paper.

Secondly, note that the most important aspect of the distinction between owning and renting arises from the transaction cost for selling houses. In the absence of the transaction cost, the recursive structure of the problem implies that in addition to the household's age, only the beginning-of-period networth and income are relevant state variables. In other words, if there was no transaction cost, we could think of homeowners as simply purchasing the house always only for one period, and thus at the beginning of the period -after selling the house and paying back the mortgage- it is irrelevant whether a household owned or rented in the previous period. However, with the transaction cost in place, homeowners have the option of not selling their house and thus not incuring the cost. This creates inertia in homeowners' adjustments to changes in the economic environment. Hence the quantity of housing owned at the beginning of the period, $H_{t-1}$, becomes a state variable. To account for mobility profiles over the life-cycle observed in the data, the shock $M_{t}$ potentially forcing a household to move is a reduced-form way of modeling that homeowners may have to move and sell their house for reasons exogenous to the model, such as job-related relocations etc.

Thirdly, the elasticity parameter $\eta$ in the utility function in equation 8 shapes the life-cycle home ownership decision of the household in an important way. To see this, first note that there are two basic channels in this model that determine the household's optimal ownership decision: 
I will refer to the first as the "user-cost" channel and the second as the "life-cycle" channel. The "user-cost" channel is based on comparison of the contemporaneous costs and benefits of owning versus renting, and has a long tradition in the analysis of the ownership decision 2 . The "life-cycle" channel comes from the household's desire to equalize marginal utilities across life-cycle periods. The young household faces a life-cycle labor income profile with a deterministic component that is increasing but not tradable. One way for this young household to borrow against the future labor income is to buy a large house and take out a large mortgage to finance this purchase, and in this way smooth consumption along the housing services dimension.

This is where the elasticity parameter becomes important: for high levels of complementarity between housing services and other goods, the household would ideally like to frequently adjust the level of housing services as its income and hence numeraire consumption rise during the early part of its life-cycle. However, the transaction cost punishes frequent upgrades in house size, and the down payment requirement makes a house that would also be large enough later in life unaffordable to the young household. Thus, if housing services and numeraire consumption are very complementary, the down payment constraint in equation 3 is more effective in preventing young households from becoming home owners than for cases in which the two goods are closer to substitutes.

\section{Empirical Strategy and Data}

\subsection{Estimation Procedure}

\section{Overview}

The goal of the empirical approach is to infer changes in short-term household expectations and the significance of downpayment constraints over the period of the recent housing boom. In order to do this, I use the cross-sections from years 1995, 1998, 2001, 2004 and 2007 of the Survey of Consumer Finances (SCF), which contains detailed information on the wealth composition and income of a representative sample of U.S. households? Since the data are only available in three-

\footnotetext{
${ }^{2}$ See Himmelberg, Mayer, and Sinai (2005) for a recent application.

${ }^{3}$ The Federal Reserve conducts the survey every three years. The SCF oversamples rich households who hold the majority of aggregate U.S. wealth, but also provides sampling weights that can be used to calculate statistics based on a representative U.S. sample. This paper only computes means and variances from the SCF using the sampling weights.
} 
year increments, I set the length of a model period to three years. I estimate the parameters of the utility function, which I restrict to be identical for all periods, and expected house price growth $\left\{m_{t}\right\}_{t}$ and average down payments requirements $\left\{\delta_{t}\right\}_{t}$, which I allow to take different values for each period.

\section{Structure of Household Beliefs}

Some assumptions about household belief formation are necessary to execute the estimation. First, I assume that households have short-term beliefs about price growth over the next three years, and long-term beliefs about all following life-cycle periods. The long-term beliefs are set to long-run averages based on past observed house price growth and volatility. The short-term mean is allowed to vary from period to period, hence being a potential source of short-term swings in household choices. In the current setup, I also keep the short-term variance of household beliefs fixed at the long-term value, and thus focus on the effect of changes in expected appreciation rates keeping the level of uncertainty constant. I further do not allow for heterogeneity in household beliefs.

To state the structure of household beliefs more concisely, let $t$ denote the calendar dates in three-year increments, with $t=1$ corresponding to $1995, t=2$ to 1998 , and so on. At each date $t$, a household optimizing at this date faces an interest rate $r_{t}=R_{t}-1$, a rent-to-price ratio $\alpha_{t}$, a mortgage spread $\zeta_{t}$, and a minimum down payment share $\delta_{t}$. Further, the household believes that mean house price growth until $t+1$ is given by $m_{t}$. Table 1 shows short-run parameter values for each year.

\begin{tabular}{cccccc}
\hline Year $t$ & $r_{t}$ & $\alpha_{t}$ & $\zeta_{t}$ & $\delta_{t}$ & $m_{t}$ \\
\hline 1995 & $3.42 \%$ & $7.18 \%$ & $1.67 \%$ & $*$ & $*$ \\
1998 & $3.24 \%$ & $7.07 \%$ & $1.87 \%$ & $*$ & $*$ \\
2001 & $0.86 \%$ & $6.15 \%$ & $3.35 \%$ & $*$ & $*$ \\
2004 & $0.73 \%$ & $5.09 \%$ & $2.21 \%$ & $*$ & $*$ \\
2007 & $2.23 \%$ & $4.45 \%$ & $2.01 \%$ & & \\
\hline
\end{tabular}

Table 1: Short-run Parameters. $r_{t}$ is real annual interest rate implied by yield on treasuries with 3 years to maturity. $\alpha_{t}$ is rent-to-price ratio calculated by rescaling 1992 base value of 0.07 over time. $\zeta_{t}$ is annual spread of 30-year mortgage rate over $r_{t}$. ${ }^{*}$ Minimum down payment (as percentage of house value) $\delta_{t}$ and expected appreciation $m_{t}$ are to be estimated.

Interest rate, rent-to-price ratio and mortgage spread are observable both to the household and 
the econometrician in the short-term, and I assume that at date $t$ households sign savings, rental, or mortgage contracts until $t+1$ subject to the rates listed in the table. To calculate the rentto-house-price ratio, I deflate the aggregate Case-Shiller house price index by the CPI for rental prices to obtain a series for the price-to-rent ratio. I then take the value of $7 \%$ reported by the 1992 Residential Finance Survey and extrapolate this number over the sample period by scaling it with the inverse of the Case-Shiller/CPI index growth.

The expected house price growth $m_{t}$ as defined in equation 11 is a latent parameter and will be inferred from observed household choices.

I further assume that households must on average at least pay for $\delta_{t}$ percent of the house value from their own funds when purchasing a house. Note that this parameter does not specify the average size of the down payments actually made by households. It rather determines the minimum possible down payment allowed. Generally, evidence on this parameter could be compiled from data on observed mortgage contracts that were offered by banks and mortgage brokers during the 1995 to 2007 time period. However, the approach taken in this paper is to infer this parameter from observed household choices jointly with expectations and utility parameters, under the assumption that each household can borrow at the terms characterized by $\left(r_{t}, \zeta_{t}, \delta_{t}\right)$.

Table 1 specifies beliefs for a household optimizing at date $t$ over the next period. One still needs to specify household beliefs for all remaining life-cycle periods, i.e. for dates $t+s, s>0$. These long-run beliefs are constant and set to long-run averages of the data series for the variables in table 1. Table 2 shows these long-run values.

\begin{tabular}{lr}
\hline Parameter & Value \\
\hline Interest rate $r_{t+s}$ & $3 \%$ \\
Rent-to-price ratio $\alpha_{t+s}$ & $6.5 \%$ \\
Mortgage spread $\zeta_{t+s}$ & $2.25 \%$ \\
Minimum down payment $\delta_{t+s}$ & $20 \%$ \\
Expected price growth $m_{t+s}$ & $1 \%$ \\
\hline
\end{tabular}

Table 2: Long-run Beliefs $(s>0)$.

The way in which household beliefs are "rolling forward" through time is best illustrated by means of an example. Consider a household at date $t=1$ (i.e. in 1995). From table1, we know that 
this household is facing an interest rate of $3.42 \%$, a rent-to-price ratio of $7.18 \%$, a mortgage spread of $1.67 \%$, and a down payment requirement of $\delta_{1995}$ percent. Further, this household believes that house price will grow by $m_{1995}$ percent until 1998. For all dates beyond 1998, the household believes that the values of these variables are given in table 2 . In other words, the household believes that the interest rate is $r_{t+s}=3 \%$, the rent-to-price ratio $\alpha_{t+s}=6.5 \%$, etc., for all dates with $s>0$. Once time passes and the household gets to date $t=2(1998)$, the realizations of the variables are given by the values in table 1, and now the household believes that the long-run values from table 2 apply to all dates beyond 2001.

This structure of beliefs is consistent with mean reversion, in the sense that households believe that variables fluctuate in the short-run but always return to long-run averages. In addition, it is a computationally tractable approach.

\section{Model-to-Data Mapping}

The data do not have a panel structure, hence each year-t-sample is a cross-section of different households. Keeping this in mind, index households for each year by $i=1, \ldots, N_{t}$ (with $i$ generally indexing a different household in years $t$ and $t+1$ ). Then for each year $t$, I construct a sample $S_{t} \equiv\left\{a_{i t}, \tau_{i t-1}, W_{i t}, P_{t} H_{i t-1}, Y_{i t}\right\}_{i=1}^{N_{t}}$ from the SCF, where $a_{i t}$ is the household age, $\tau_{i t-1}$ indicates ownership status (rent vs. own), and the remaining variables denote networth, house value, and labor income as defined in the previous section. When combining this sample with the year- $t$ house price $P_{t}$, all state variables of the model are available for each household.

Denote the vector of short-run model parameters for year $t$, corresponding to table 1 in the previous section, as $\theta_{t}$, and the vector of long-run parameters corresponding to table 2 as $\theta^{L R}$. Given the model's optimal policy conditional on parameters, it is possible to calculate the optimal choices for each household in the sample, $Z\left(S_{t}, \theta_{t}, \theta^{L R}\right)=\left\{C_{i t}, \tau_{i t}, L_{i t}, H_{i t}\right\}_{i=1}^{N_{t}}$, with $C_{i t}$ denoting numeraire consumption, $\tau_{i t}$ next period's ownership status, $L_{i t}$ the mortgage or savings amount, and $H_{i t}$ the size of the house being rented or owned in the next period. These year- $t$ choices can in turn be mapped to year- $t+1$ state variables by using the $t+1$ price level $P_{t+1}$ and by simulating income shocks for the individual observations. Applying the model to sample $S_{t}$ in this way thus leads to a simulated sample of next year's state variables $\hat{S}_{t+1}\left(S_{t}, \theta_{t}, \theta^{L R}\right)$, that is a function of this 
year's observed state variables and the model paramters denoted by $\theta_{t}$ and $\theta^{L R}$.

The estimation procedure essentially entails finding the parameter vectors $\left\{\hat{\theta}_{t}\right\}_{t=1995}^{2004}$ that minimizes the distance (in a method-of-moments sense) of the simulated $t+1$-samples $\hat{S}_{t+1}$ constructed in the way outlined above, and the observed $t+1$-samples $S_{t+1}$ for each of the years $t=1995,1998$, 2001 and 2004. Thus it is a Simulated Method of Moments (SMM) approach applied to a dynamic model and repeated cross-sections.

Due to computational limitations I do not estimate all parameters of the model. Specifically, I estimate the elasticity parameter $\eta$ and the weight on housing services consumption $\rho$ since these are the preference parameters directly related to housing choices. I restrict these parameters to stay constant over all years included in the estimation, hence ruling out an exogenous shock to preferences as explanation of the shift in housing demand. Further, I estimate for each year the expected price growth $m_{t}$, and the minimum downpaymwent share $\delta_{t}$, which can be regarded as the average constraint that households face when taking out a mortgage. All other parameters are set to values that previous studies of the housing market have determined through their research. I give details in the next section.

To implement the belief structure in practice, I solve the dynamic program once with parameter vector $\theta^{L R}$ to obtain the long-run value function $v_{a}^{L R}$ for each age group $a$. I then solve the dynamic program a second time separately for each year with parameter vectors $\theta_{t}$ and using $v_{a}^{L R}$ as continuation value.

\section{Estimation}

As objective function for the estimation step I use a weighted sum of squared deviations of a set of data averages from averages of the simulated sample. Since the data are repeated cross-sections and the model is dynamic in nature, a pseudo-panel approach is needed to apply the SMM approach described above.

The basic methodology follows Browning, Deaton, and Irish (1985). Using the same notation as above, let $\hat{S}_{t}$ and $S_{t}$ denote the simulated and the data samples for year $t$, respectively. Since the sample $\hat{S}_{t}$ was generated by applying the model solution to the year- $t$ data sample $S_{t-1}$, these samples generally consist of different individual households, so it is not possible to state moment 
conditions at the level of an individual observation. However, one can divide each sample into $Q$ cells based on observed characteristics that are stable between times $t$ and $t+1$, which here is a three-year period between two consecutive SCF samples. Index cells by $q=1, \ldots, Q$, and let $g_{q t}=g\left(q, S_{t}\right)$ denote a $K$-vector of sample means for cell $q$ in year $t$, where in the application the elements of $g_{q t}$ are the average homeownership rate, the value-to-income ratio and the loan-tovalue ratio (i.e. $K=3$ ). In practice, I use six birth cohorts and three education groups to get a total of $Q=18$ cells. Let the vector $\hat{g}_{q t}(\theta) \equiv g\left(q, \hat{S}_{t} ; \theta^{L R}, \theta_{t}\right)$ denote the vector of sample means for the same variables, but computed from the simulated sample. By treating each cell $q$ as an observation with variables taking on the values of cell means, I can hence create a pseudo-panel with $Q$ observations.

Let $g_{q}$ and $\hat{g}_{q}(\theta)$ denote the $T K$-vectors of the stacked cell means for all $T$ years. Then the $T K$ sample moment conditions are

$$
\frac{1}{Q} \sum_{q=1}^{Q} g_{q}-\hat{g}_{q}(\theta) \equiv G_{Q}-\hat{G}_{Q}(\theta)=0,
$$

and for the case of fewer than $T K$ parameters in $\theta$, the Generalized Method of Moments (GMM) objective function to be minimized in $\theta$ is

$$
\left(G_{Q}-\hat{G}_{Q}(\theta)\right)^{\prime} D\left(G_{Q}-\hat{G}_{Q}(\theta)\right)
$$

where $D$ is a positive definite weighting matrix. I use the inverse variance-covariance matrix of the data moments for $D$, i.e. $D=\hat{\operatorname{Cov}}\left(g_{q}\right)^{-1}$. Note that $G_{Q}$ and $\hat{G}_{Q}$ are simply the aggregate sample means in the real and simulated data, for all $K$ variables and $T$ years. However, for the computation of the estimated variance-covariance matrix of the moment conditions, it is necessary to have the pseudo-panel structure and a well-defined notion of an observation.

Equation 15 is a conventional GMM objective function with a constant weighting matrix, and the asymptotic standard errors can generally be obtained in the well-known way (see e.g. Wooldridge (2002)). Since this is a simulation estimator, the estimated covariance matrix of the moment conditions needs to be adjusted by a factor taking into account the number of simulations. Appendix B contains details on how the standard errors are calculated, drawing on the econometric results of Pakes and Pollard (1989) and Hall and Rust (2002). 


\subsection{Other Parameters}

Table 3 shows those parameters of the model that I do not estimate and that do not vary over the time period included in the estimation.

\begin{tabular}{lr}
\hline Parameter & Value \\
\hline Risk-aversion $\gamma$ & 5 \\
Discount factor $\beta$ & 0.96 \\
Sales transaction cost $\nu$ & $7 \%$ \\
Maintenance share $\psi$ & $2.5 \%$ \\
Std.Dev. $\left(\epsilon_{1, t}\right)$ & $11 \%$ \\
Std.Dev. $\left(\epsilon_{2, i t}\right)$ & $13 \%$ \\
Corr $\left(\epsilon_{1, t}, \epsilon_{2, i t}\right)$ & $20 \%$ \\
Income growth $g$ & $1 \%$ \\
Years of bequest annuity $J$ & 7.5 \\
\hline
\end{tabular}

Table 3: Time-invariant Parameters

All parameters are annual. The coefficient of relative risk aversion and the discount rate are set to conventional values found in micro-level studies. The sales transaction cost and the maintenance share are in line with the values used by other studies of the housing market, and are at the lower end of what was found by Li, Liu, and Yao (2009). The transaction cost reflects the actual cost of selling such as realtor's fees and the cost of moving for homeowners (over renters). The maintenance share is the fraction of the house value that homeowners have to spend to offset depreciation.

The bequest strength (in years of annuity to be paid to descendants) is a parameter with relatively weak empirical evidence from the literature, and hence I set it to a reasonable value that facilitates the overall fit of the model. The annual standard deviation of the shock to permanent income growth is set to $13 \%$ based on the results of Cocco, Gomes, and Maenhout (2005). The standard deviation of house price growth is set to $11 \%$, which corresponds to long-run moments of aggregate U.S. house price indices such as the Case-Shiller house price index. The correlation of both shocks is set to $20 \%$, a value somewhat higher than the empirical correlation between aggregate income and aggregate house prices. This is meant to reflect the higher correlation of regional or idiosyncratic house price growth with regional or idiosyncratic income growth.

During the estimation step, three additional time-varying inputs are required. These are the 
current house price level $P_{t}$, the realized price growth from $t$ to $t+1, \Delta P_{t+1}$, and the realized aggregate income growth $\Delta \bar{Y}_{t+1}$. The price level is required since it is a state variable of the model, and hence necessary to evaluate the model's policy function. Both the realized price and income growth are needed to compute the transition from the year- $t$ sample of choices $Z_{t}$ to the year- $t+1$ simulated sample of state variables $\hat{S}_{t+1}$.

Table 4 lists the time series of these inputs for years 1995 to 2007.

\begin{tabular}{cccc}
\hline Year $t$ & $P_{t}$ & $\Delta P_{t+1}$ & $\Delta \bar{Y}_{t+1}$ \\
\hline 1995 & 1.31 & 0.03 & 0.09 \\
1998 & 1.34 & 0.18 & 0.11 \\
2001 & 1.58 & 0.27 & 0.08 \\
2004 & 2.00 & 0.16 & 0.08 \\
2007 & 2.32 & & \\
\hline
\end{tabular}

Table 4: House Price Level, House Price Growth, and Aggregate Income Growth. $P_{t}$ is re-nomarlized deflated Case-Shiller index. $\Delta \bar{Y}_{t+1}$ is real disposable income growth.

The aggregate house price levels are obtained by re-normalizing the deflated Case-Shiller index (for numerical purposes). Note that the absolute size of the price levels is irrelevant since the price is in units of numeraire consumption per units of the housing asset, which produces an equal amount of housing services per year. The utility from housing services consumption is determined by its relative weight $\rho$ in the utility function. This is one of the parameters to be estimated, and is hence free to scale the prices. Put simply, rescaling the prices listed in the table will only rescale the estimated value of $\rho$. Hence only the relative change in the price level over time is important. The last column of table 4 lists real aggregate income growth for the three-year periods, as implied by the NIPA disposable household income.

Finally, I take three sets of parameters from the literature that enter the houshold problem due to its life-cycle character.

- The deterministic part of labor income growth $(f(a)$ in equation 12 follows a third-degree polynomial whose coefficients are taken from Cocco, Gomes, and Maenhout (2005), and thus are consistent with the shock to income growth. Specifically, I use coefficients decsribing the income profile of high-school graduates estimated by Cocco, Gomes, and Maenhout (2005) 
using data from the PSID. The life-cyle profile has the common hump-shape.

- The survival probabilities $\lambda_{a}$ are computed from the mortality rates reported by the National Center of Health Statistics.

- For the life-cycle profile of mobility (i.e. the probailities of moving) I use the estimates by Li, Liu, and Yao (2009), who use PSID data. The basic shape of the mobility rate function over the life-cycle is convex and declining in age.

\subsection{Data}

For each of the years 1995, 1998, 2001, 2004 and 2007, I use the prepared extract sample of the SCF4. I remove all observations with the household head being younger than 25 years of age, which is the starting age of the life-cycle labor income profile I use. I take labor income to be broadly definined as the sum of wage income, income from social security and other retirement funds, income from own businesses, and government transfers. As defintion of networth, I use the pre-generated variable "networth" from the SCF, which is the balance of all household assets and liabilities. For the house value of homeowners, I use the SCF variable "houses", which is the value of the primary residence 5 , As the mortgage principal of homeowners, I use the SCF variable "mrthel", which includes home equity loans and other types of loans that use the primary residence as collateral.

Further, I remove all households with more than 5 million dollars of networth (in year 2000 dollars) from the sample. The life-cycle income process of these very wealthy households is usually not well described by the one assumed in equation 12 , since a large fraction of their income is from dividends and capital gains. The problem is aggravated by the fact that these households tend be be older, with traditional sources of retirement income only being a very small fraction of their overall income. The removal of these households has the additional advantage of being able to economize on grid points during the estimation. The disadvantage is a loss of about $15 \%$ of raw observations for each year, but due to the strong oversampling of wealthy households in the

\footnotetext{
${ }^{4}$ These samples already contain some pre-generated variables, and some observations with unlikely answers have been removed.

${ }^{5}$ This implies that other real estate investments of the household will be included in networth and hence are counted as savings in the sense of the model.
} 
SCF this only amounts to about $1.5 \%$ of effective observations after applying the SCF-provided sampling weights.

\begin{tabular}{|c|c|c|c|c|c|c|}
\hline Year & Tenure & \# Obs & $\begin{array}{c}(1) \\
\text { Income }\end{array}$ & $\begin{array}{c}(2) \\
\text { Networth }\end{array}$ & $\begin{array}{c}(3) \\
\text { House } \\
\text { Value }\end{array}$ & $\begin{array}{c}(4) \\
\text { Mortgage }\end{array}$ \\
\hline \multirow[t]{3}{*}{1995} & Own & 2436 & $\begin{array}{l}49,309 \\
(48,078)\end{array}$ & $\begin{array}{l}216,822 \\
(363,028)\end{array}$ & $\begin{array}{c}110,787 \\
(93,875)\end{array}$ & $\begin{array}{l}40,080 \\
(54,901)\end{array}$ \\
\hline & Rent & 795 & 28,911 & 47,540 & & \\
\hline & & & $(31,122)$ & $(128,224)$ & & \\
\hline \multirow[t]{2}{*}{1998} & Own & 1715 & $\begin{array}{l}54,263 \\
(50,592)\end{array}$ & $\begin{array}{l}286,748 \\
(492,297)\end{array}$ & $\begin{array}{l}129,821 \\
(117,259)\end{array}$ & $\begin{array}{l}48,120 \\
(64,373)\end{array}$ \\
\hline & Rent & 677 & $\begin{array}{r}30,498 \\
(27,627) \\
\end{array}$ & $\begin{array}{r}56,426 \\
(170,552) \\
\end{array}$ & & \\
\hline \multirow[t]{2}{*}{2001} & Own & 2341 & $\begin{array}{l}63,266 \\
(55,749)\end{array}$ & $\begin{array}{l}360,931 \\
(556,081)\end{array}$ & $\begin{array}{l}165,052 \\
(158,883)\end{array}$ & $\begin{array}{l}57,534 \\
(78,517)\end{array}$ \\
\hline & Rent & 909 & $\begin{array}{l}33,074 \\
(29,965)\end{array}$ & $\begin{array}{r}63,224 \\
(221,123) \\
\end{array}$ & & \\
\hline \multirow[t]{2}{*}{2004} & Own & 2420 & $\begin{array}{l}68,988 \\
(59,909)\end{array}$ & $\begin{array}{l}401,417 \\
(602,875)\end{array}$ & $\begin{array}{l}223,233 \\
(221,725)\end{array}$ & $\begin{array}{c}81,498 \\
(102,745)\end{array}$ \\
\hline & Rent & 857 & $\begin{array}{l}34,960 \\
(35,261)\end{array}$ & $\begin{array}{c}49,882 \\
(176,395)\end{array}$ & & \\
\hline \multirow[t]{2}{*}{2007} & Own & 2380 & $\begin{array}{l}75,130 \\
(67,118)\end{array}$ & $\begin{array}{l}460,062 \\
(695,903)\end{array}$ & $\begin{array}{l}266,784 \\
(258,438)\end{array}$ & $\begin{array}{c}98,390 \\
(129,239)\end{array}$ \\
\hline & Rent & 766 & $\begin{array}{l}38,045 \\
(36,259)\end{array}$ & $\begin{array}{c}72,219 \\
(243,336)\end{array}$ & & \\
\hline
\end{tabular}

Table 5: Descriptive Statistics from Survey of Consumer Finances. All estimates calculated using SCF weights.

Table 5 shows means and standard deviations of the variables by ownership status for all sample years. All statistics are computed using the SCF weights to create a representative sample, and the number of observations are adjusted for the SCF replication technique (i.e. the actual number of observations was divided by 5). The units for columns 1 through 4 are nominal dollars. Households who rent are on average much poorer than households that live in their own home, both in terms of income and wealth. Over the sample period income and wealth of homeowners also exhibit a higher growth rate. 


\section{Results}

\subsection{Target Moments and Estimation Results}

As moments in the objective function, I use the average homeownership rate, the value-to-income ratio and the loan-to-value ratio for each of the years 1998, 2001, 2004, and 2007. This gives 12 moments and 6 parameters when only the utility parameters and the means of the house price growth process are estimated. Four parameters are added when the minimum downpayment shares are estimated in addition. Table 6 displays the targeted moments. All moments are sample means computed using SCF sampling weights. House values and loan-to-value ratios are reported only for homeowners (and are zero for renters). The choice of these moments rests mainly on their natural connection to model quantities. The homeownership rate is calculated as the sample average of households' discrete own-versus-rent decisions. Similarly, the house value-to-income ratio is the sample average of a state variable of the model, and the loan-to-value ratio is the ratio of two choice variables, mortgage principal and house value. The model is designed to capture several important features of homeownership, house size, and general life-cycle mortgage dynamics; hence these moments represent the set of quantities that the model is best suited to match. The model also makes predictions about the household networth-to-income ratio, but due to the lack of other, higher-yielding assets such as stocks, it is impossible for the model to match general wealth dynamics in a period like the late 1990s, and thus I do not include this moment in the set of targets.

\begin{tabular}{cccc}
\hline Year & Homeownership Rate & Value-to-Income Ratio & Loan-to-Value Ratio \\
\hline 1995 & 71.21 & 4.141 & 0.3385 \\
1998 & 72.11 & 4.795 & 0.3516 \\
2001 & 73.83 & 4.345 & 0.3485 \\
2004 & 75.58 & 4.886 & 0.3747 \\
2007 & 75.15 & 5.328 & 0.3670 \\
\hline
\end{tabular}

Table 6: Target Moments. VTI and LTV ratios computed for the subsample of homeowners.

I use aggregate moments since all parameters are assumed to be identical across age and income groups. However, because the model's key mechanisms rest on its life-cycle character, I wil examine the "fit" across age groups in the next section to see whether the general life-cycle shape of model- 


\begin{tabular}{lcccc}
\hline Parameter & \multicolumn{2}{c}{$(1) \delta=0.2$} & \multicolumn{2}{c}{$(2) \delta$ flexible } \\
\hline$\eta$ & 0.5840 & $(0.1445)$ & 0.4050 & $(0.1877)$ \\
$\rho$ & 0.2126 & $(0.0263)$ & 0.1681 & $(0.0477)$ \\
\hline$m_{1995}$ & 0.0248 & $(0.0426)$ & 0.0956 & $(0.0369)$ \\
$m_{1998}$ & 0.0383 & $(0.0189)$ & 0.0811 & $(0.0328)$ \\
$m_{2001}$ & 0.0200 & $(0.0287)$ & 0.0225 & $(0.0244)$ \\
$m_{2004}$ & 0.0229 & $(0.0189)$ & -0.0019 & $(0.0028)$ \\
\hline$\delta_{1995}$ & & & 0.2895 & $(0.1270)$ \\
$\delta_{1998}$ & & & 0.2077 & $(0.1341)$ \\
$\delta_{2001}$ & & & 0.1519 & $(0.0764)$ \\
$\delta_{2004}$ & & & 0.1431 & $(0.0636)$ \\
\hline
\end{tabular}

Table 7: Estimation Results. Asymptotic standard errors in parenthesis. See text for details.

implied moments lines up with their data counterparts.

Table 7 shows results of the estimation step. The asymptotic standard errors in parenthesis are calculated using the GMM formula for the case with a constant weighting matrix. Appendix B contains details on how the standard errors were computed. Specification (1) keeps the short-run minimum downpayment shares $\delta_{t}$ exogenously fixed at the long-run value of 0.2 , while specification (2) also estimates these parameters.

In both specifications the (intra-temporal) elasticity of substitution between numeraire consumption and housing services consumption takes on values of 0.6 or lower, which indicates a high degree of complemetarity between the two goods and is in line with what other micro-studies have found. The weight on housing services $\rho$ does not have a direct interpretation; in combination with the price level $P_{t}$ it pins down the expenditure share on housing services in each period.

The point estimates of the expected house price growth are reported for one model period, i.e. three years. The long-run value $m^{L R}$ is set to $3 \%$. The estimated values in specification (1) stay close to this long-run value.

In specification (2), the addition of the downpayment shares as free parameters decreased the estimated values of $\eta$ and $\rho$. The estimate of the expected return in 1995 is now markedly higher with close to $10 \%$. The expected return point estimates are decreasing over time, with about $8 \%$ in 1998 , down to only about $0 \%$ in 2004 . 
The estimates of the minimum downpayment shares also exhibit a clear declining trend. The 1998 estimate of $29 \%$ is higher than the long-run value of $20 \%$, and the estimated value of $\delta_{2004}=14 \%$ is lower than the long-run level.

\subsection{Identification}

In the following, I will explore the sources of identification for the result: 6 . First, I will analyze the features of the data that compel the estimates of the expectations and borrowing constraints conditional on the utility parameters being given by their estimates in specification (2) of table 7 . Then I will argue what drives the results with respect to the parameters $\eta$ and $\rho$.

\section{Expectations and Down Payment Constraints}

The goal of the estimation is to infer the quantitative importance of expectations and down payment constraints from observed household choices along three margins: (i) extensive housing demand, i.e. the own vs. rent decision, (ii) intensive housing demand, i.e. the optimal quantity of housing, and (iii) the optimal leverage of homeowners.

Identification between the two forces -expectations and down payment constraints- comes from their differential effect on the three optimal choice margins. In general, both factors have opposing effects on the three outcomes.

Higher expectations increase both the optimal house size as well as optimal leverage, since they increase the expected return to the housing asset and thus the expected excess return of the housing asset over the risk-free bond. They also lower the user cost of housing, making owning relatively more attractive for a given house-price-to-rent ratio. This effect may be dampened by the down payment constraint, however. Ultimately, if a household does not have sufficient liquidity for the down payment of a larger house, then increasing the degree of this household's optimism will not improve the its ability to purchase the house.

An increase of the down payment requirement lowers the home ownership rate and loan-to-value ratios mechanically due to its liquidity effect. The effect of a higher down payment requirement on optimal house sizes is less clear: it changes the composition of the pool of homeowners as well

\footnotetext{
${ }^{6} \mathrm{I}$ am using the term identification loosely throughout this section as referring to those aspects of model and data interaction that allow me to tell apart the different effects.
} 
as the optimal house sizes of some households that were close to or at the constraint before an increase. However, both effects are small relative to the effects on the two other choices in general, since only households in the neighborhood of the constraint are affected. These households will either stay in the pool of homeowners and decrease their demand, or they will leave the pool of homeowners. If the unconstrained optimal house sizes of those households that drop out of the pool due to the increased constraint are not large or small relative to the average (before the change), then one would expect the total effect to be quantitatively small.

In summary, while changes in expectations affect all margins of housing demand, the down payment requirement has a relatively stronger effect on the extensive margin (own vs. rent), and relatively weaker effect on the intensive margin (optimal house size).

With these basic considerations in mind, the identification argument is best understood by proceeding in three steps. Each step involves comparing data moments to model-implied moments for a different set of expectation and borrowing constraint parameters, while the utility function parameters (elasticity $\eta$ and weight on housing $\rho$ ) are set to their values from specification (2) in table 7. First, I will consider the hypothetical case that expectations and down payment requirements stayed at their 1995 estimated values for all subsequent years. In 1995, both the expectations and down payment constraint estimates are high relative to the other years. Figure 1 displays the three data moments and the model-implied moments for this case.

The dashed lines show the target home ownership rates, house value-to-income ratios, and loanto-value ratios for all years. The solid dark lines show the corresponding model-implied moments when the expected price growth $m_{t}=9.56 \%$ and the dowpayment constraint $\delta_{t}=28.95 \%$ for all years. The model-implied value-to-income ratios in panel (B) are much too large relative to the data for years 2004 and 2007 and this combination of estimates. Low interest rates and high realized price growth push up house values in these years. Furthermore, the complementarity of numeraire and housing consumption causes the optimal house values to rise with the house price level (instead of substituting away from housing in response to the increase in relative prices). As a result, the model's optimal policy would induce households to buy too large houses if they were also optimistic about future house price growth. 
Panel (A)

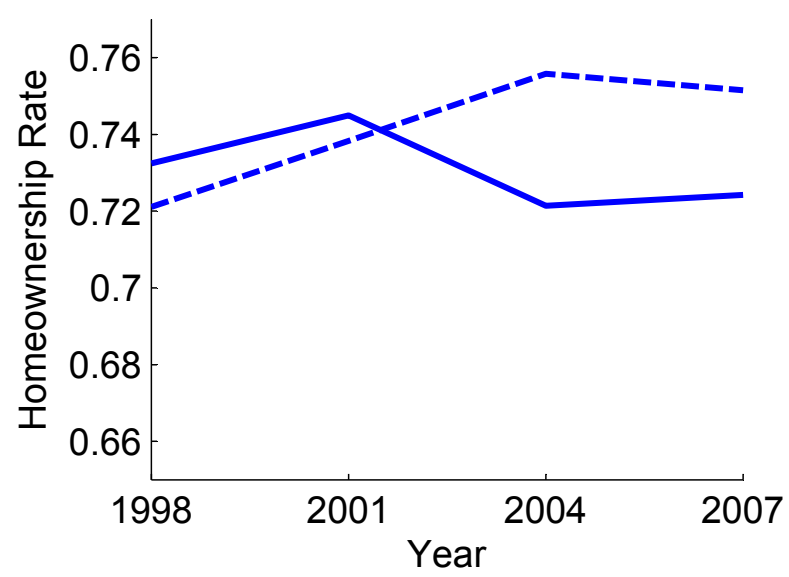

Panel (C)



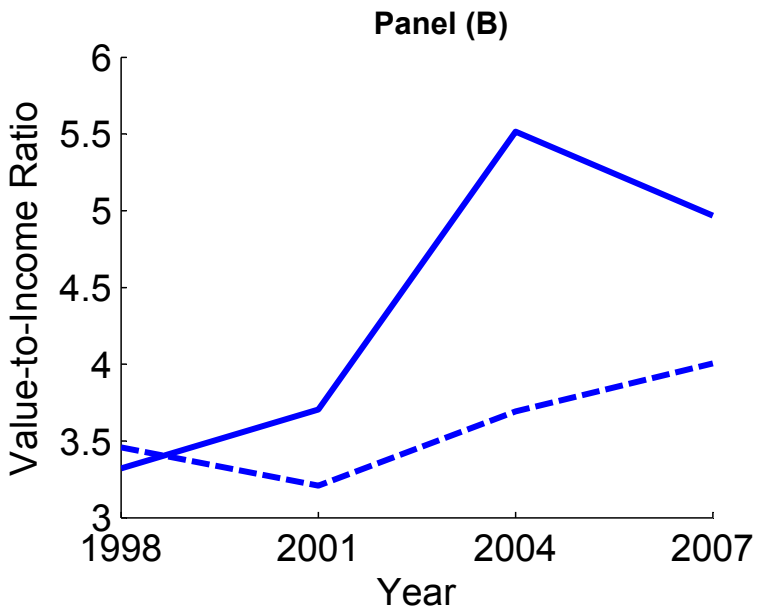

Figure 1: Target and model-generated moments with high expectations and high down payment constraints. Panel (A) shows home ownership rates, panel (B) value-to-income ratios, and panel (C) loan-to-value ratios. High house price growth expectations lead to a counterfactually large increase in value-to-income ratios.

As argued above, loosening the down payment constraint would only have a limited effect on optimal house sizes. Hence lower price growth expectations are needed in order for the modelimplied value-to-income ratios to be closer to the true ratios observed in the data. Figure 2 displays the second case of parameters. The expectations for all years are set to their actual estimated values from specification (2) in table 7, while the down payment constraint is kept at the high 1995 value.

The light solid line in panel (B) of figure 2 illustrate that progressively lowering the expectations over time has the effect of moving value-to-income ratios closer to the data targets. However, this improvement comes at the expense of substantially too low model-implied home ownership rates 
Panel (A)

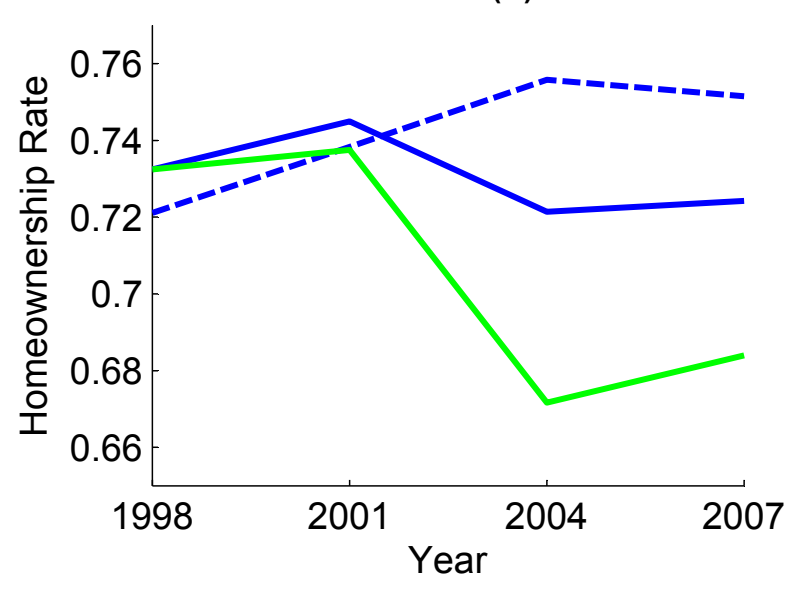

Panel (C)

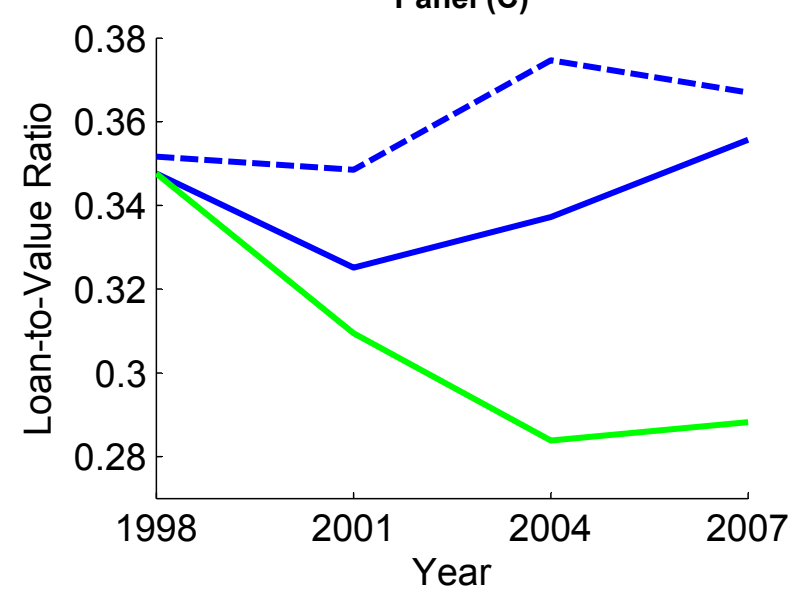

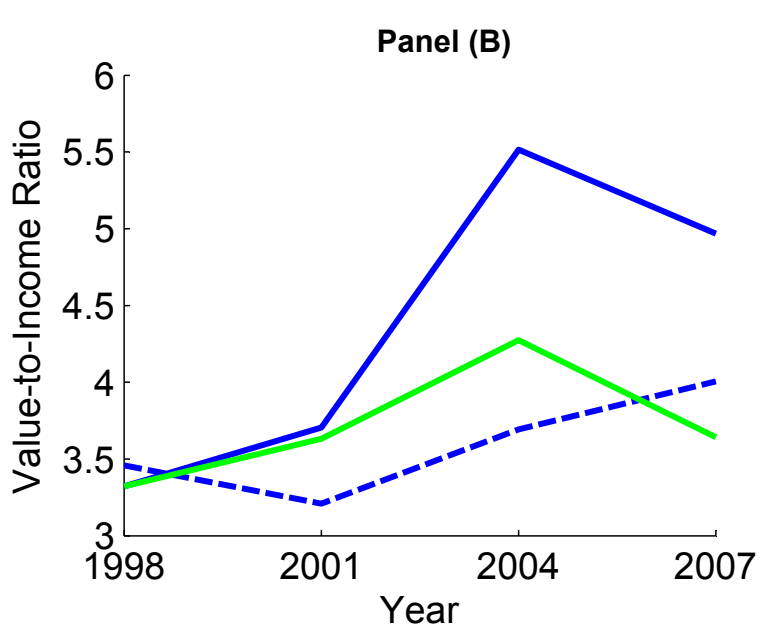

Figure 2: Target and model-generated moments with declining expectations and high down payment constraints. Panel (A) shows home ownership rates, panel (B) value-to-income ratios, and panel (C) loanto-value ratios. Progressively lower expectations induce model-implied value-to-income ratios to be closer to the data values.

and loan-to-value ratios, as can be seen in panels (A) and (C) of figure 2. Therefore, lower down payment constraints are necessary to induce higher loan-to-value ratios and home ownership rates to match the data moments. This yields the final estimates displayed in figure 3 , The model achieves a close fit of aggregate home ownership rates and loan-to-value ratios, and somewhat overfits valueto-income ratios in all years but the first. However, as argued above, relaxing the down payment constraint does not have a strong effect on the intensive margin, and hence the model-implied value-to-income ratios at the final estimates are only moved up slightly by the lowering of the credit constraint when compared to the case with low expectations and high credit constraints. 

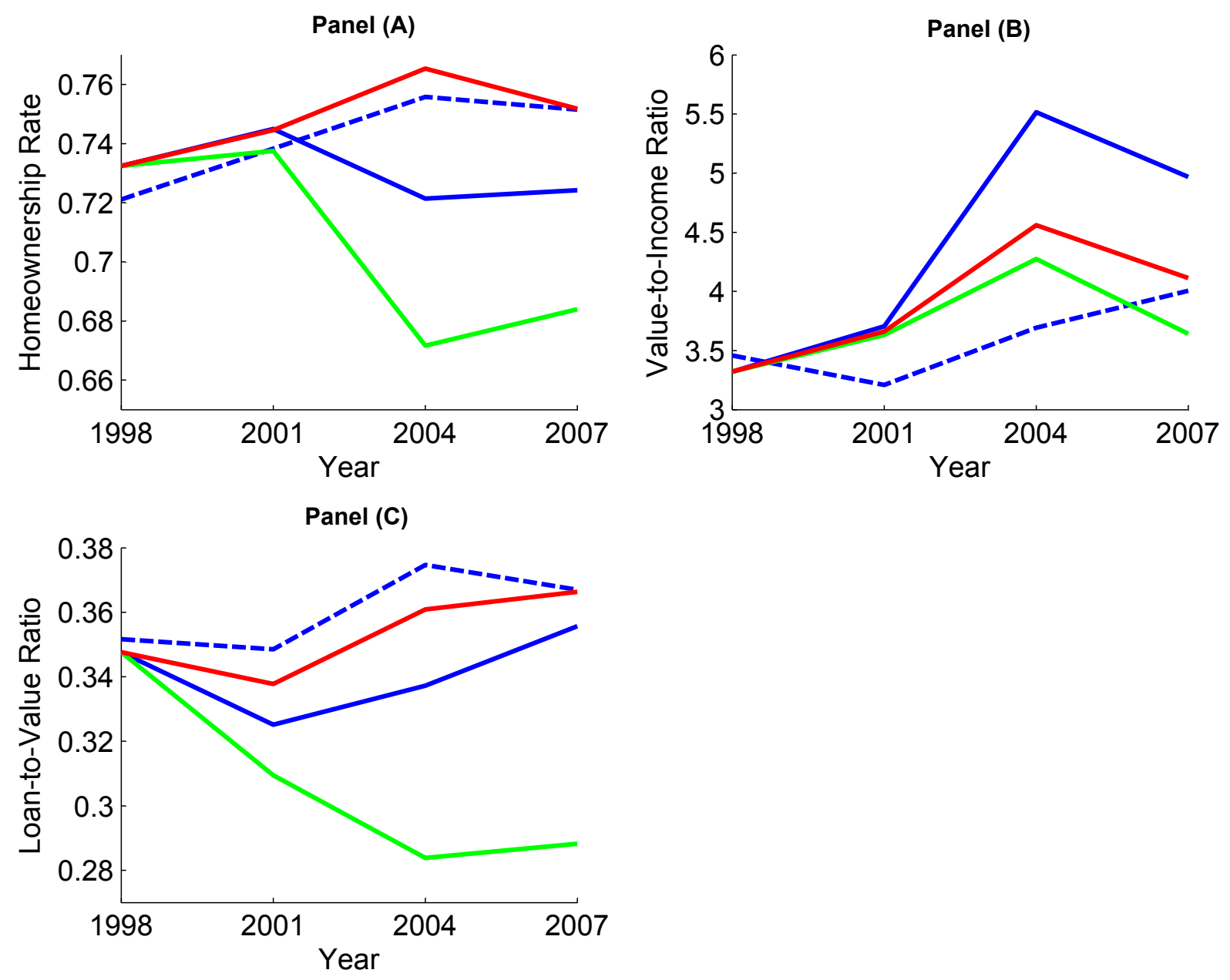

Figure 3: Target and model-generated moments with declining expectations and down payment constraints. Panel (A) shows home ownership rates, panel (B) value-to-income ratios, and panel (C) loan-to-value ratios. The solid red line plots the model-implied moments when all parameters are set to the estimates of specification (2) in table 7. Looser down payment constraints counteract the effect of low house price growth expectations to match the slight increase in homeownership rates and loan-to-value ratios, while their effect on value-to-income ratios is relatively small.

To summarize, the declining house price growth expectations are necessary to rationalize the only moderate increase in value-to-income ratios over time. With higher price growth expectations, the model's optimal policy would predict too large house values as a result of low interest rates, strongly increasing house prices, and complementarity between housing and numeraire consumption. The drop in down payment requirements is then identified from the slight rise in home ownership rates and loan-to-value ratios that occurs despite the downward trend in expectations. 


\section{Preference Parameters}

Since I constrain the elasticity parameter $\eta$ and the weight on housing $\rho$ to be identical for all years, the values of these parameters are identified from cross-sectional variation as well as variation over time.

The weight on housing $\rho$ controls the optimal expenditure on housing services and is pinned down by the average level of house value-to-income ratios over time. This parameter is stable and precisely estimated among all specifications. I briefly discussed its interaction with the price level in section 3.2.

We can think of the level of observed homeownership rates as primary source of identification for the elasticity parameter $\eta$. The hump-shaped life-cycle profile of labor income in combination with the transaction cost and borrowing constraint make it optimal for young households to save until they can afford the downpayment for a house of sufficient size (in units of housing services generated), since they want to avoid buying a small house first and then having to incur the transaction cost for upgrading later. When the elasticity of substitution between both consumption goods is low (and the goods are complements), it is very important for households to own a house of a certain size, in the sense that the house generates a sufficiently high amount of services given the income path of the household. When the elasticity parameter is higher, the household is more willing to compromise by buying a relatively smaller house and making up for this by consuming more of the numeraire good as it gets wealthier. The down payment constraint hence has a stronger effect at low elasticities, as it prevents more households from being able to afford a house of the desired size.

We can gauge the importance of the complementarity for matching target home ownership rates by conducting a constrained estimation that sets the elasticity $\eta$ to a value greater than one, implying that housing and numeraire consumption are substitutes. Based on the reasoning above, this should lead ceteris paribus to higher home ownership rates. Table 8 shows the results for this constrained estimation with $\eta=1.4$, and for easy comparison again the results of the unconstrained baseline estimation from table 7 .

To compensate for the diminished effectiveness of the borrowing constraint, the $\delta$ 's in the 


\begin{tabular}{lcccc}
\hline Parameter & \multicolumn{2}{c}{$(1) \eta=1.4$} & \multicolumn{2}{c}{ (2) baseline } \\
\hline$\eta$ & & & 0.4050 & $(0.1877)$ \\
$\rho$ & 0.1777 & $(0.0079)$ & 0.1681 & $(0.0477)$ \\
\hline$m_{1995}$ & 0.0927 & $(0.0548)$ & 0.0956 & $(0.0369)$ \\
$m_{1998}$ & 0.0561 & $(0.0270)$ & 0.0811 & $(0.0328)$ \\
$m_{2001}$ & 0.0322 & $(0.0148)$ & 0.0225 & $(0.0244)$ \\
$m_{2004}$ & 0.0450 & $(0.0761)$ & -0.0019 & $(0.0028)$ \\
\hline$\delta_{1995}$ & 0.3307 & $(0.0742)$ & 0.2895 & $(0.1270)$ \\
$\delta_{1998}$ & 0.2764 & $(0.1143)$ & 0.2077 & $(0.1341)$ \\
$\delta_{2001}$ & 0.1898 & $(0.0173)$ & 0.1519 & $(0.0764)$ \\
$\delta_{2004}$ & 0.1419 & $(0.1533)$ & 0.1431 & $(0.0636)$ \\
\hline
\end{tabular}

Table 8: Results of constrained estimation with $\eta=1.4$. Asymptotic standard errors in parenthesis. See text for details.

constrained estimation are higher than in the baseline case for all years but 20047 . In addition, the downward trend of the expectations estimates is less pronounced in the constrained case. The lack of a strong downward trend is consistent with the intuition that due to the higher subtitutability between housing and numeraire consumption, house values (= housing expenditure) do not rise as much with house prices, and hence expectations need to fall less to match the data profile of value-to-income ratios.

These deviations of the estimates in the constrained case from the baseline case show the importance of complementarity between housing services and other goods for the baseline results. The fact that the estimation cannot "use" the elasticity parameter in the constrained case to match the level of home ownership rates leads to a considerably worse fit. The higher down payment estimates compared to the baseline case have taken on the job of keeping the home ownership rate low. Of course, their higher level has the side-effect of moving the other model-implied moments further away from their data targets when compared to the baseline specification.

Abstracting from the mechanics of the optimal fit, the key identifying factor for the low elasticity estimate is that it raises the importance of the down payment constraint in determining the own vs. rent decision. At high elasticities, the constraint is less powerful in keeping households from

\footnotetext{
${ }^{7}$ In 2004 , the very low rent-to-price ratio seems to be sufficient to keep down the ownership rate for the highelasticity household.
} 
buying a house. The two potential explanations of household choices considered in the framework of this estimation exercise are expectations and down payment constraints. By making the latter less important for the extensive margin, a high elasticity effectively diminishes the model's explanatory power with respect to one margin of household choices.

\subsection{Model Fit}

While I do not target age-disaggregated moments during the estimation, the model generates much of the heterogeneity in housing choices along the age dimension. Hence in the following I will briefly examine the age profiles of the model-implied home ownership rates, value-to-income ratios and loan-to-value ratios, and compare them to their data counterparts. All graphs in this section show model-implied moments for 1998 (the first year in the estimation) when evaluated at the parameter estimates from specification (2) in table 7. The fit in later years is comparable.

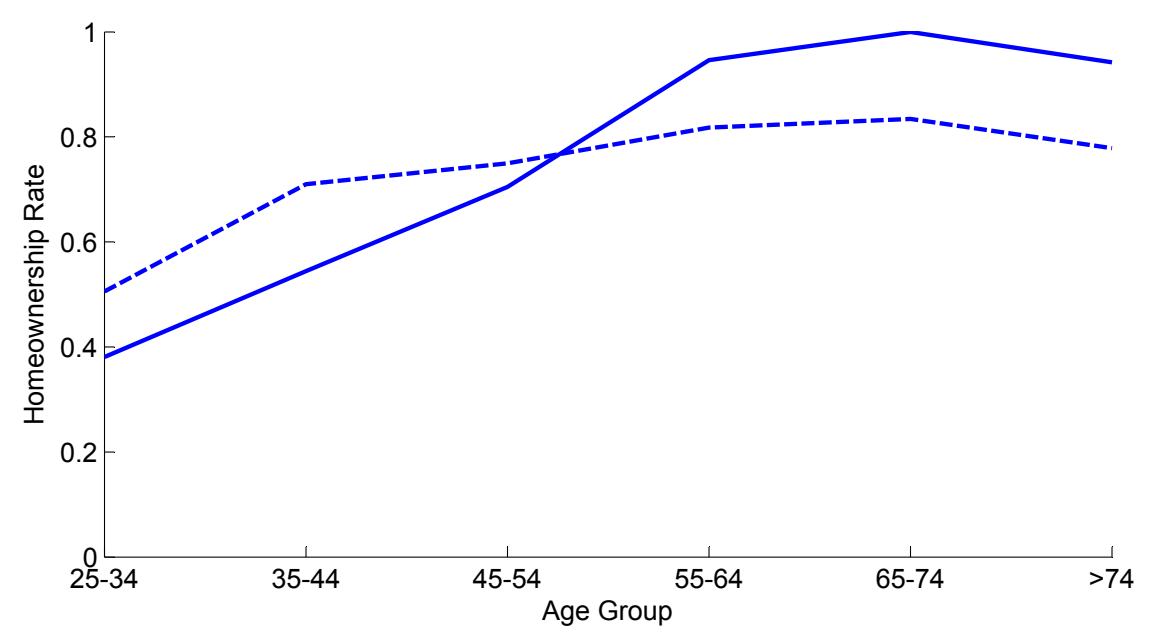

Figure 4: Age profile of home ownership rate in 1998. Means by age group using SCF weights. Dashed line: data, solid line: model.

Figure 4 displays the age profile of data and model-implied moments in 1998. The model manages to match the genral shape of the life-cycle profile of home ownership. It somewhat overstates the importance of the borrowing constraint and the resulting savings behavior of young households. Consequently, the life-cycle shape of the model homeownership rates is more pronounced than in the data.

Figure 5 shows data and model value-to-income ratios for 1998. Again, the overall fit of the 


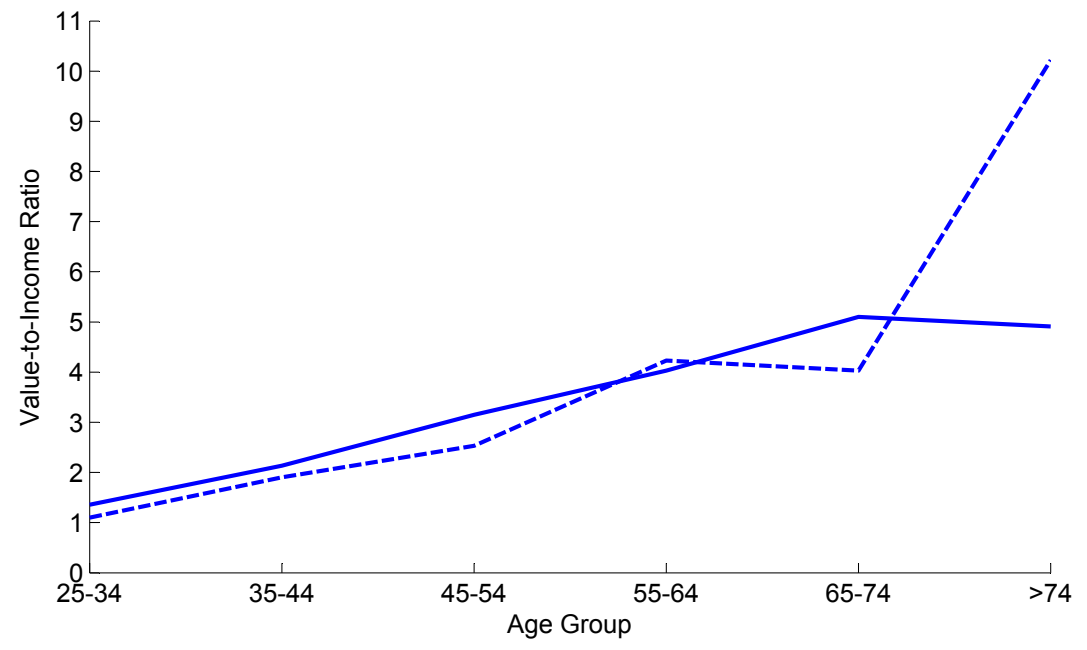

Figure 5: Age profile of value-to-income ratios in 1998. Means by age group using SCF weights. Dashed line: data, solid line: model.

model matches magnitudes and the life-cycle trend. However, the fit is slightly too flat when compared to the data, and concave instead of convex; especially for old households the model cannot replicate the sharp increase in value-to-income ratios. This may also have to do with inaccurate measurement of the replacement income after retirement, and hence overstated VTI ratios in the data.

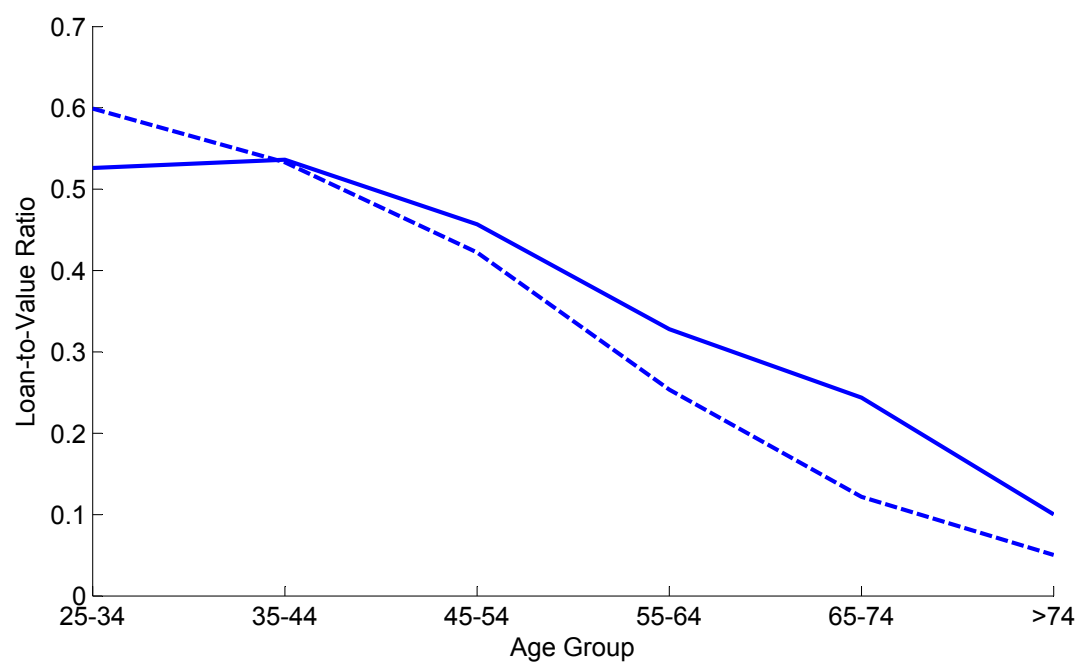

Figure 6: Age profile of loan-to-value ratios in 1998. Means by age group using SCF weights. Dashed line: data, solid line: model.

Finally, figure 6 shows data and model loan-to-value ratios for 1998 . The model is able to 
generate the close-to-linear decline of the loan-to-value ratio profiles in the data. Similar to the homeownership rate, the model overstates the effect of the downpayment constraint: leverage is slightly too low for young households and too high for old households. All these discrepancies mostly originate from the fact that the only source of age-specific heterogeneity in the model is the combination of a hump-shaped labor income profile and the down payment constraint. The model slightly "overuses" the resulting optimal life-cycle saving and borrowing decisions when matching aggregate moments. This is not necessarily surprising, since in reality there exist several other factors that affect households' life-cycle profile of housing demand such as family size, which I did not include in the model.

\subsection{Robustness}

A natural question with respect to the estimation is how sensitive the results are to changes of calibrated parameters, particularly the long-run beliefs about interest rates, house price and income growth, and the down payment constraint. Table 9 contains a selection of estimation results for variations of these parameters.

The first column lists estimation results for the case when the long-run belief of the interest rate is low with $r^{L R}=1 \%$ instead of $3 \%$. In the second column, I consider the case of beliefs in low long-run down payment constraints with $\delta^{L R}=10 \%$ instead of $20 \%$. The third column shows results for high long-run house price growth expectations of $2 \%$ annually instead of $1 \%$, and the last column shows the symmetric case for long-run income growth beliefs (i.e. $g=2 \%$ instead of $1 \%)$.

The general features of the baseline specification from table 7 are preserved for all variations of long-run beliefs considered here: complementarity between housing service and numeraire consumption, and generally declining trends of house price growth expectations and down payment constraints. The only exceptions are the case of high long-run income growth (last column), where the expectations estimates are trending upwards again in 2004, and the case of low long-run interest rates (first column), where the borrowing constraint estimate for 2001 is lower than for 2004 .

There are two main lessons I take away from these results. First, the general trends of declining short-run expectations and down payment constraints seem to be relatively robust to variations in 


\begin{tabular}{lrrrr}
\hline Parameter & Low $r$ & Low $\delta^{L R}$ & High $m^{L R}$ & High $g$ \\
\hline$\eta$ & 0.251 & 0.252 & 0.400 & 0.425 \\
$\rho$ & 0.148 & 0.135 & 0.157 & 0.198 \\
\hline$m_{1995}$ & 0.120 & 0.160 & 0.142 & 0.121 \\
$m_{1998}$ & 0.080 & 0.080 & 0.080 & 0.005 \\
$m_{2001}$ & 0.026 & 0.033 & 0.018 & -0.018 \\
$m_{2004}$ & -0.008 & 0.024 & 0.005 & 0.021 \\
\hline$\delta_{1995}$ & 0.281 & 0.299 & 0.293 & 0.289 \\
$\delta_{1998}$ & 0.275 & 0.250 & 0.275 & 0.206 \\
$\delta_{2001}$ & 0.150 & 0.181 & 0.194 & 0.170 \\
$\delta_{2004}$ & 0.173 & 0.174 & 0.146 & 0.160 \\
\hline
\end{tabular}

Table 9: Estimation results for different long-run belief specifications.

long-run beliefs. Secondly, apart from the general trends, the exact point estimates vary considerably with different assumption about long-run beliefs.

Finally, the results in the last column suggest that the interaction of house price growth and income growth expectations is important for the optimal housing demand and hence the resulting expectations estimates. The question of how exactly these beliefs interact and whether income growth expectations can be inferred from observed household choices jointly with house price expectations will be left for future research.

\section{Conclusion}

This paper estimates short-run expectations of house price appreciation and minimum down payment requirements during the recent housing boom. The inference is based on structural estimation of a life-cycle dynamic program that encompasses housing demand choices at the extensive and intensive margin, applied to repeated cross-sections from the Survey of Consumer Finances. I implement the estimation by constructing a pseudo-panel and applying a Simulated Method of Moments estimator.

The main result is that model-implied aggregate expectations of future price growth were higher than the long-term average at the beginning of the recent housing boom, but then declined and were close to zero in 2004, before the price peak of the boom. The estimation also finds that down 
payment constraints were less strict during the boom. These findings are driven by the need for the model to jointly rationalize increases in the homeownership rate, leverage (as measured by loan-tovalue ratios), and house value-to-income ratios, in an environment of high house prices, low interest rates, and high price-to-rent ratios. The decline in expected house price gains is needed to moderate the otherwise to steep increase of value-to-income ratios predicted by the model. Everything else equal, the low price growth expectations would depress loan-to-value ratios and the home ownership rate. The role of the the relaxed downpayment constraint is thus to offset the effect of the falling expectations and induce slight increases in leverage and home ownership to match the data. The separate identification of the two forces (expectations and down payment constraints) affecting household choices comes from their differential impact on the intensive and extensive margins of housing demand. In particular, changes of the down payment constraint only have a quantitatively small effect on the average value-to-income ratio.

The elasticity of substitution between housing services and other goods plays a key role in identifying the expectations. It is the complementarity between the two goods that causes optimal housing expenditure to rise as the relative price of housing increases. At high price growth expectations, this would lead to a counterfactually large rise in value-to-income ratios, and hence the falling expecations take on the role of dampening this increase. The low estimate of the elasticity itself is identified from the fact that, only at low values (i.e. complementarity), the down payment constraint is sufficiently powerful in determining the level of the home ownership rate.

Overall, the quantitative results are consistent with households expecting a downward correction of house prices relative to incomes in the late phase of the boom. This finding could be interpreted as evidence for aggregate household beliefs in mean-reverting house prices, in the sense that they expect long-run future price growth to follow the historical average of roughly $1 \%$ real growth per year.

Apart from the quantitative results, the paper's main methodological contribution is the way in which I infer subjective short-run expectations by closely tracking household choices over time using a life-cycle portfolio choice model. An important aspect of the method is that it takes into account short-term movements of other variables that characterize the economic environment for 
housing choices, while keeping household expectations of the long-term values of these variables set to their long-run averages.

The results of this paper do not contradict the notion that the recent housing boom was partly fueled by overly optimistic expectations of house price appreciation. Only a relatively small share of the housing stock gets traded per year, and these transactions form the basis for price measurement. It is hence possible that few very optimistic households caused the price spike by increasing shortterm demand in local housing markets - Piazzesi and Schneider (2009) make this point using a simple search model. Aggregate beliefs, however, are also identified from observing the majority of households who did not substantially adjust their housing choices during the boom.

It would be an interesting extension to allow heterogeneous beliefs across age or income groups to see whether the approach taken here could identify those subgroups with optimistic beliefs that presumably were the driving force behind the strong price movement.

\section{References}

Bajari, P., P. Chan, D. Krueger, and D. Miller (2010): "A Dynamic Model of Housing Demand: Estimation and Policy Implications," Working paper.

Browning, M., A. Deaton, and M. Irish (1985): "A profitable approach to labor supply and commodity demands over the life-cycle," Econometrica, 53(3), 503-543.

Campbell, J. Y., And J. F. Cocco (2003): "Household risk management and optimal mortgage choice," Quarterly Journal of Economics, Nov, 1449-1494.

Case, K. E., And R. J. Shiller (2003): "Is there a bubble in the housing market?," Brookings Papers on Economic Activity, 2, 299-361.

Cocco, J. F. (2004): "Portfolio Choice in the Presence of Housing," Review of Financial Studies, $18(2), 535-567$.

Cocco, J. F., F. J. Gomes, and P. J. Maenhout (2005): "Consumption and Portfolio Choice over the Life-Cycle," Review of Financial Studies, 18(2), 492-533. 
Hall, G., And J. Rust (2002): "Econometric Methods for Endogenously sampled time series: the Case of Commodity Price Speculation in the Steel Market," Working paper.

Himmelberg, C., C. Mayer, and T. Sinai (2005): "Assessing high house prices: bubbles, fundamentals and misperceptions," Journal of Economic Perspectives, 19(4), 67-92.

Li, W., H. Liu, and R. Yao (2009): "Housing over Time and over the Life Cycle," Federal Reserve Bank of Philadelphia Working Paper, NO. 09-7.

Li, W., And R. Yao (2007): "The Life-Cycle Effects of House Price Changes," Journal of Money, Credit and Banking, 39(6), 1375-1409.

Mayer, C., K. Pence, and S. Sherlund (2009): "The Rise in Mortgage Defaults," Journal of Economic Perspectives, 23, 27-50.

Mian, A., And A. Sufi (2009): "House Prices, Home Equity-Based Borrowing, and the U.S. Household Leverage Crisis," Working Paper.

Pakes, A., And D. Pollard (1989): "Simulation and the Asymptotics of Optimization Estimators," Econometrica, 57(5), 1027-1057.

Piazzesi, M., And M. Schneider (2009): "Momentum Traders in the Housing Market: Survey Evidence and a Search Model," American Economic Review PESP.

Wooldridge, J. M. (2002): Econometric Analysis of Cross Section and Panel Data. MIT Press, Cambridge.

YaO, R., and H. H. Zhang (2005a): "Optimal Consumption and Portfolio Choices with Risky Housing and Borrowing Constraints," Review of Financial Studies, 18(1), 197-239.

(2005b): "Optimal Life-Cycle Asset Allocation with Housing as Collateral," Working Paper. 


\section{A Dynamic Programming Solution}

First, denote the value function of the household who did not own a house or has sold its house as $v_{t}^{M}\left(P_{t}, w_{t}\right)$, where $w_{t}=W_{t} / Y_{t}$ and $W_{t}$ is defined as in equation 9 in the main text. $v_{t}^{M}(\cdot)$ is further defined as the value conditional on survival until age $a_{t+1}$, and after all shocks are realized. Thus one gets

$$
v_{t}^{M}\left(P_{t}, w_{t}\right)=\max _{c_{t}, l_{t}, \tau_{t}, h_{t}} u\left(c_{t}, \frac{h_{t}}{P_{t}}\right)+\beta \mathrm{E}_{t}\left[v_{t+1}\left(x_{t+1}\right) \exp \left(f\left(a_{t+1}\right)+\epsilon_{2, t+1}\right)\right]
$$

subject to

$$
\begin{aligned}
& w_{t}=c_{t}+l_{t}+\left(1-\tau_{t}\right) \alpha_{t} h_{t}+\tau_{t}(1+\psi) h_{t}, \\
& l_{t} \geq-\tau_{t}\left(1-\delta_{t}\right) h_{t} .
\end{aligned}
$$

where $v_{t}\left(x_{t}\right)$ is defined as in equation 10 , the constraints 17 and 18 are obtained by normalizing the budget constraint 4 and the downpayment constraint 3 by income $Y_{t}$, and the utility function $u(c, h / P)$ is of the CES-form as defined in equation 8. Secondly, denote the value function of a homeowner who is forced to stay in the same house as $v_{t}^{S}\left(P_{t}, w_{t}, \bar{h}_{t-1}\right)$. Again, I define $v_{t}^{S}(\cdot)$ as the value conditional on survival until $a_{t+1}$, and after realization of the move shock. This yields

$$
v_{t}^{S}\left(P_{t}, w_{t}, \bar{h}_{t-1}\right)=\max _{c_{t}, l_{t}} u\left(c_{t}, \frac{\bar{h}_{t-1}}{P_{t}}\right)+\beta \mathrm{E}_{t}\left[v_{t+1}\left(x_{t+1}\right) \exp \left(f\left(a_{t+1}\right)+\epsilon_{2, t+1}\right)\right]
$$

subject to

$$
\begin{gathered}
w_{t}+\nu \bar{h}_{t-1}=c_{t}+l_{t}+(1+\psi) \bar{h}_{t-1} . \\
l_{t} \geq-\left(1-\delta_{t}\right) \bar{h}_{t-1} .
\end{gathered}
$$

Due to the definition of $w_{t}$ as including the house value net of the transaction cost, the household that stays in the same house receives this cost back on the LHS of budget constraint 20. Thus the house value $\bar{h}_{t-1}$ cancels on both sides of the constraint, i.e. the constraint becomes

$$
1+\left(R_{t}+1\left[l_{t-1}<0\right] \zeta_{t}\right) l_{t-1}=c_{t}+l_{t}+\psi \bar{h}_{t-1} .
$$


One can now express the normalized value function $v_{t}(\cdot)$ in terms of $v_{t}^{M}(\cdot)$ and $v_{t}^{S}(\cdot)$

$$
\begin{aligned}
v_{t}\left(\tau_{t-1}, M_{t}, P_{t}, w_{t}, \bar{h}_{t-1}\right)= & \lambda_{t+1}\left[\tau_{t-1}\left(1-M_{t}\right) \max \left\{v_{t}^{M}\left(P_{t}, w_{t}\right), v_{t}^{S}\left(P_{t}, w_{t}, \bar{h}_{t-1}\right)\right\}\right. \\
& \left.+\left(1-\tau_{t-1}+\tau_{t-1} M_{t}\right) v_{t}^{M}\left(P_{t}, w_{t}\right)\right] \\
& +\left(1-\lambda_{t+1}\right) b\left(P_{t}, w_{t}\right) .
\end{aligned}
$$

Note that in the presence of the maintanance cost $\psi \bar{h}_{t-1}$ certain assumptions on the parameters are necessary in order to guarantee that positive consumption is feasible for the problem defined by equation 19 and constraints 20 and 21; essentially, the household's funds after re-purchasing the house and borrowing the maximum amount, $1+\left(R_{t}+1\left[l_{t-1}<0\right] \zeta_{t}\right) l_{t-1}+\left(1-\delta_{t}\right) \bar{h}_{t-1}$, must be greater than the total maintanance cost $\psi \bar{h}_{t-1}$. This condition may be violated in situations when the household has borrowed a large amount in the previous period (i.e. $l_{t-1}<<0$ ), and the return on housing had a particularly bad realization so that the house lost value, i.e. $P_{t-1}>P_{t}$. Since the expected return to housing is a parameter to be estimated, it is not possible to generally rule out these cases with parametric assumptions. One solution is to simply set $v_{t}^{S}(\cdot)=-\infty$ in these cases, which is what I do.

Further, if the only restriction on the return to housing is the requirment that it remains greater than $-100 \%$, then a particularly negative realization of the return may cause $w_{t}$ to be negative for a homeowner with a large mortgage. This of course implies $v_{t}^{S}(\cdot)=-\infty$ based on the discussion above, but it also means that the household could not consume anything even if it sold its house and paid off its mortgage. In such cases, in order for the problem posed in equation 16 to be welldefined, the homeowner is forced to default on its mortgage, have its house seized, and buy housing services in the rental market. It will also have to pay a fraction $\xi$ of its income as cost of defaulting. In other words, for these cases I simply set $v_{t}^{S}\left(P_{t}, w_{t}, \bar{h}_{t-1}\right)=-\infty$ and $v_{t}^{M}\left(P_{t}, w_{t}\right)=v_{t}^{M}\left(P_{t}, 1-\xi\right)$. I use a value of $\xi=0.1$ throughout.

While it is technically important to have a clean way of dealing with these cases, particularly since the expected return to housing is unrestricted during estimation, they are practically not relevant, since the SCF only contains few households with negative networth, and to my knowledge no households for which the sum of networth and income is negative 8 . In addition, when the model

\footnotetext{
${ }^{8}$ This is not to say that giving the household the additional choice of defaulting at any realization of shocks would
} 
is evaluated at the final estimated parameters in table 7, the case of default never occurs in the model's solution.

To complete the description of the transformed model, I still need to state the form of the bequest function $b\left(P_{t}, w_{t}\right)$ in the last line of equation 22 , and the transition equations for the transformed state variables.

With respect to the bequest function, I follow Yao and Zhang (2005a) in assuming that in the case of its death the household wants to buy a $J$-year annuity for the recipients of the bequest, and receives terminal utility equivalent to the annuity being spent on numeraire and housing consumption according to a Cobb-Douglas share on housing of $\omega$. In other words, after its death, the household's liquid wealth $w_{t}$ is used to buy $L$ years of numeraire and housing services consumption that are the optimal demands at year- $j$ prices and for a Cobb-Douglas utility function, i.e. $u_{b}(C, S)=\left(C^{1-\omega} S^{\omega}\right)^{1-\gamma} /(1-\gamma)$. Thus the bequest utility for the problem normalized by income is

$$
b\left(P_{t}, w_{t}\right)=\frac{\beta\left(1-\beta^{J}\right)\left[A_{t}^{J} w_{t} \omega^{\omega}(1-\omega)^{1-\omega}\right]^{1-\gamma}}{(1-\beta)(1-\gamma)\left(\alpha_{t} P_{t}\right)^{\omega(1-\gamma)}}
$$

where $A_{t}^{J}$ is the $J$-year annuity factor

$$
A_{t}^{J}=\frac{\left(R_{t}-1\right) R_{t}^{J}}{R_{t}^{J}-1}
$$

The assumption to base bequest utility on a Cobb-Douglas form is merely for convenience and ease of interpretation. The decisive feature is that bequest utilty is increasing in terminal wealth, and the strength of the bequest motive can be controlled through the parameter $J$. One could as well define the bequest utility based on the CES-form as defined in equation 8. This yields a substantially more complicated expression for $b\left(P_{t}, w_{t}\right)$, and the bequest function looses its simple interpretation as annuity since the CES-form does not imply constant expenditure shares on the two goods, see e.g. Li, Liu, and Yao (2009) for details. The functional form chosen in equation 23 introduces the additional paramter $\omega$, that I set to 0.2 in line with long-run averages of the expenditure share on housing.

The three continuous state variables of the model are $P_{t}, w_{t}$, and $\bar{h}_{t-1}$. The transition equation not be a potentially interesting extension of the model. However, the analysis of default decisions is not the focus of this paper. 
for $P_{t}$ is unaffected by the normalization and thus still given by equation 11 . The transitions for $w_{t}$ and $\bar{h}_{t-1}$ are

$$
\begin{aligned}
w_{t+1} & =\left[\left(R_{t}+1\left[\hat{l}_{t}<0\right] \zeta_{t}\right) \hat{l}_{t}+\hat{\tau}_{t}(1-\nu) \hat{h}_{t} e^{\kappa_{t+1}}\right] \exp \left(-f\left(a_{t+1}\right)-\epsilon_{2, t+1}\right)+1, \\
\bar{h}_{t} & =\hat{\tau}_{t} \hat{h}_{t} \exp \left(\epsilon_{1, t+1}-f\left(a_{t+1}\right)-\epsilon_{2, t+1}\right),
\end{aligned}
$$

where $\hat{l}_{t}, \hat{h}_{t}$, and $\hat{\tau}_{t}$ denote the optimal savings and housing policies for period $t$.

The dynamic program specified by equations 16 to 25 can be solved recursively starting in period $T$, where

$$
v_{t}\left(x_{t}\right)=b\left(P_{t}, w_{t}\right)
$$

since $\lambda_{T+1}=0$. To compute the value functions $v_{t}^{M}(\cdot)$ and $v_{t}^{S}(\cdot)$ in practice, I discretize the continuous state variables $P_{t}, w_{t}$, and $\bar{h}_{t-1}$ on grids with 40 points each. The spacing of the grid points for $w_{t}$ and $\bar{h}_{t-1}$ is chosen with the goal of estimation in mind such that the points are denser on intervals where more households from the SCF are located. Further, the boundaries are chosen such that almost all observations fall within the state space. For the computation of the expected continuation value, it is necessary to specify the joint distribution of the shocks to the house price growth $\epsilon_{1, t+1}$ and to income growth $\epsilon_{2, t+1}$. For computational speed, I assume the two shocks follow a joint binomial distribution. In practice, this means that each shock has a high and a low outcome, and there are a total of 4 possible states. By setting probabilities for these states and the values of the high and the low outcomes, any value of the first and second moments of the joint distribution of the two shocks can be achieved. Experimentation with a joint Gaussian distribution and associated quadrature techniques with up to 10 quadrature points for each dimension did not lead to significantly different results. The shock forcing a homeowner to move $M_{t+1}$ is independent of both the house price and income shocks, and distributed as a $\{0,1\}$-Bernoulli random variable with $\operatorname{Pr}\left(M_{t+1}=1\right)$ set according to table 3 . I use cubic spline interpolation to compute the continuation value in case the the next period state variables do not lie on the grid. 


\section{B Estimation Procedure}

Define the year- $t$ sample of variables from the SCF that correspond to the model's normalized state variables

$$
s_{t}=\left\{a_{i t}, \tau_{i t-1}, w_{i t}, \bar{h}_{i t-1}\right\}_{i=1}^{N_{t}},
$$

where as defined in section $3, a_{i t}$ is the age of the household head for observation $i$. The goal is to create the model-implied sample $\hat{s}_{t+1}\left(s_{t}, \theta\right)$ of simulated year- $t+1$ state variables. From the transition equations for the state variables 24 and 24 it is clear that the required ingredients for this step are

- the model policy functions $\hat{l}_{a}\left(x_{t} ; \theta\right), \hat{h}_{a}\left(x_{t} ; \theta\right)$, and $\hat{\tau}_{a}\left(x_{t} ; \theta\right)$, where $x_{t}=\left[M_{t}, P_{t}, \tau_{t}, w_{t}, \bar{h}_{t-1}\right]$ are the model state variables,

- simulated random variables for the move shock $M_{t}$ and the shock to income growth $\epsilon_{t+1}$ for each observation,

- and the aggregate price level $P_{t}$, and the realized return to housing $P_{t+1} / P_{t}$.

In the following, I will state the algorithm to be applied to each observation of sample $s_{t}$ in order to construct the simulate sample $\hat{s}_{t+1}$.

1. Take observation $i$ from sample $s_{t}$. Dropping the observation and time subscripts, denote age by $a$, the liquid funds by $w$, homeownership status by $\tau$, and the value of the house owned or rented by $\bar{h}$. Denote the aggregate house price level by $P$ and the realized aggregate return to housing from $t$ to $t+1$ as $R^{H}$.

2. If $\tau=1$, that is the current observation is a homeowner, draw a uniform random variable $u_{1}$ and simulate move shock $M=1\left[u_{1}<\operatorname{Pr}(M=1 \mid a)\right]$, where $1[\cdot]$ denotes the indicator function.

3. Using the optimal policies from the model's computational solution with parameter vector $\theta$, 
calculate the model-implied household choices

$$
\begin{aligned}
l & =\hat{l}_{a}(M, P, w, \tau, \bar{h} ; \theta) \\
\tau^{\prime} & =\hat{\tau}_{a}(M, P, w, \tau, \bar{h} ; \theta) \\
h & =\hat{h}_{a}(M, P, w, \tau, \bar{h} ; \theta) .
\end{aligned}
$$

4. Draw a uniform random variable $u_{2}$ and simulate income growth shock $\epsilon=1\left[u_{2}>0.5\right] \epsilon_{\text {high }}+$ $\left(1-1\left[u_{2}>0.5\right]\right) \epsilon_{l o w}$

5. Apply the transition equation for the state variables to get the next period's implied states, i.e. compute

$$
\begin{aligned}
w^{\prime} & =\left[(R+1[l<0] \zeta) l+\tau^{\prime}(1-\nu) h R^{H}\right] \exp (-f(a+1)-\epsilon)+1 \\
\bar{h}^{\prime} & =\tau^{\prime} h R^{H} \exp (-f(a+1)-\epsilon) .
\end{aligned}
$$

6. Set $a_{i t+1}=a+1, \tau_{i t}=\tau^{\prime}, w_{i t+1}=w^{\prime}$, and $\bar{h}_{i t+1}=\bar{h}^{\prime}$ to obtain the simulated state variables for this observation for year $t+1$.

By applying this algorithm to each observation in the sample $s_{t}$ once, one obtains the simulated sample $\hat{s}_{t+1}\left(s_{t}, \theta\right)$. In practice, one needs to repeat the whole procedure multiple times with different seeds for the random number generator and obtain multiple simulated samples. During the calculation of the moments for the distance function, one then uses an average over the moments calculated from each simulation. Denote the number of simulations conducted by $Z$. All estimation results reported in this paper are computed with $Z=5$, which turns out to be sufficient to get stable results.

After repeating this procedure for each pair of consecutive years, one has the complete set of data and simulated samples, $s_{t+1}$ and $\hat{s}_{t+1}\left(s_{t}, \theta\right)$.

Given these samples, the computation of moments and the construction of the GMM objective function proceeds as outlined in the main text. Denote by $g_{q}$ the $T K$-vector of data means for birth cohort-education cell $q$, and by $\hat{g}_{q}$ the corresponding vector of simulated means, the aggregate moment conditions are computed as in equation 14, and the estimator for $\theta$ is defined based on 
equation 15 as

$$
\hat{\theta}=\operatorname{argmin}_{\theta}\left(G_{Q}-\hat{G}_{Q}(\theta)\right)^{\prime} D\left(G_{Q}-\hat{G}_{Q}(\theta)\right) .
$$

To minimize this distance function, I employ a pattern search algorithm over a range of model parameters for which the dynamic programming solution is well-behaved. This algorithm is essentially an intelligent grid search that only uses direct function evaluation and does not compute any numerical derivatives. While it is relatively slow, it performs well for objective functions that are not completely smooth, such as the objective function in this application. The reason for the lack of smoothness is that it is impossible to interpolate between the model's policies if an observation's state variables do not directly lie on the policy grid. In other words, step 3 in the algorithm above involves assigning model-implied optimal policies defined on the state space grid of $40 \times 40 \times 40$ points to each observation in the SCF. This creates the problem that very small changes in parameter values may not cause any observation to "flip" to an adjacent grid point on the optimal policy grid. However, a slightly larger change may cause multiple observation at once to move to a different policy $9^{9}$ The discreteness of homeownership choices (rent vs. keep old house vs. sell and buy new) creates discontinuities of the optimal policy functions, which make interpolation at the level of individual observations impossible.

However, due to the relatively large number of observations, the objective is sufficiently smooth to be numerically differentiable using bi-directional differentiation at a delta of 0.01 . While this should be sufficient to calculate approximate gradients for standard errors once the minimum is found, it leads to problems with convergence for minimization algorithms based on numerical derivatives. The pattern search algorithm is robust to the lack of smoothness, since it can be configured to refine its search grid only to the level of precision that the numerical properties of the objective function allow, and does not rely on a gradient-based convergence criterion. The exact algorithm used is "pattersearch" from the MATLAB Direct Search Toolbox.

\footnotetext{
${ }^{9}$ One way to overcome this problem would of course be to increase the number of grid point for the state space. However, the model's optimal policies need to be calculated many times during the estimation with any minimization algorithm, which make this a practically infeasible solution.
} 
Based on the results of Pakes and Pollard (1989), the SMM estimator's asymptotic distribution is normal with

$$
\sqrt{Q}\left(\hat{\theta}-\theta^{*}\right) \stackrel{d}{\rightarrow} N\left(0,(1+1 / Z) \Lambda_{1}^{-1} \Lambda_{2} \Lambda_{1}^{-1}\right)
$$

To write the expressions for $\Lambda_{1}$ and $\Lambda_{2}$, first define the Jacobian matrix of the population moments with respect to the parameters evaluated at $\theta *$

$$
A=\mathrm{E}\left[\nabla_{\theta}\left(g_{q}-\hat{g}_{q}\left(\theta^{*}\right)\right)\right]
$$

Then one gets

$$
\Lambda_{1}=A^{\prime} D A
$$

and

$$
\Lambda_{2}=A^{\prime} D \Omega D A
$$

where $\Omega$ is the variance-covariance matrix of the population moments

$$
\Omega=\mathrm{E}\left[\left(g_{q}-\hat{g}_{q}\left(\theta^{*}\right)\right)\left(g_{q}-\hat{g}_{q}\left(\theta^{*}\right)\right)^{\prime}\right]
$$

A consistent estimator for the variance-covariance matrix of $\hat{\theta}$ is thus

$$
\frac{1}{Q}\left(\hat{A}^{\prime} D \hat{A}\right)^{-1}\left(\hat{A}^{\prime} D \hat{\Omega} D \hat{A}\right)\left(\hat{A}^{\prime} D \hat{A}\right)^{-1}
$$

where $\hat{A}$ and $\hat{\Omega}$ are consistent estimators of $A$ and $\Omega$ and are calculated as

$$
\begin{aligned}
& \hat{A}=\nabla_{\theta}\left(G_{Q}-\hat{G}_{Q}(\hat{\theta})\right) \text { and } \\
& \hat{\Omega}=\frac{1}{Q} \sum_{q=1}^{Q}\left(g_{q}-\hat{g}_{q}(\hat{\theta})\right)\left(g_{q}-\hat{g}_{q}(\hat{\theta})\right)^{\prime} .
\end{aligned}
$$

